\title{
PEDRO DE TOLEDO Y LA ILUMINACIÓN DE UN MISAL SEVILLANO DEL SIGLO XV
}

\author{
POR T. Laguna Paúl
}

Estudio de la iluminación de un Misal Mixto sevillano (1428-1433) realizado por el copistailuminador Pedro de Toledo que es la primera obra documentada, hasta la fecha, de este artista. En él se destaca la relación existente entre el texto e imagen a través de la información recogida en los pagos, el carácter litúrgico de la obra, y los aspectos técnicos de la miniatura reflejados en unas jerarquias decorativas que ponen de manifiesto otros aspectos muy interesantes de la iluminación de manuscritos.

Se revisa, igualmente, la personalidad artística de Pedro de Toledo dentro del contexto artístico sevillano del primer tercio del siglo XV; la problemática de las corrientes del gótico internacional en esta ciudad apoyándose en la documentación conocida y las miniaturas, datadas y datables, conservadas.

A study of the illumination of a Sevillian Misal Mixto (1428-1433) by the copyist and illuminator Pedro de Toledo, and as yet the earliest documented work by this artist. The article stresses the relationship between text and image, using information from the payments, the liturgical nature of the work, and technical aspects of the miniature as reflected in a number of decorative hierarchies which reveal other extremely interesting aspects of manuscript illumination.

The artistic figure of Pedro de Toledo is also examined within the artistic context of Seville in the first third of the 15thh century and within that of the problem of the various currents of international Gothic in this city, making use of the documentation at our disposal and the dated or datable miniatures preserved.

Los estudios sobre la miniatura sevillana se remontan a fines del siglo pasado ${ }^{1}$. Sin embargo, la primera investigación sobre los libros corales del siglo XV

1. BOUTELOU, C.: "Códices ilustrados de la Biblioteca Colombina", Museo español de Antigüedades I (1872) pp. 149 ss.. SENTENACH y CABAÑAS, N.: La pintura en Sevilla, Sevilla 1885, pp. 109 ss. 
fue llevada a cabo por D. Diego Angulo ${ }^{2}$ quien, en 1928, analizó un grupo de capitales historiadas, ochenta y tres, bastante homogéneas en el tratamiento compositivo de las escenas y orlas, y las atribuyó al que denominó Maestro de los Cipreses. Alguna de las letras, por los pagos, la asignó a Pedro de Toledo. Desde este momento, simultáneamente, D. Jesús Domínguez Bordona se hacía eco del estudio de Angulo, que debía estar todavía en prensa, y difundía la importancia y calidad de la miniatura sevillana del s. XV, así como la existencia de un taller catedralicio dedicado a la producción libraria ${ }^{3}$. La historiografía tradicional cita desde entonces, reiteradamente, las opiniones de estos dos especialistas y ha generalizado la producción de este maestro a toda la ciudad y, casi por extensión, a Pedro de Toledo. Sin embargo, desde hace tiempo, se viene observando mediante la investigación documental catedralicia que, durante el siglo $\mathrm{XV}$, los artesanos del libro que trabajaban para la catedral lo hacían pro pretio ${ }^{4}$. No podía existir, por tanto, únicamente este taller en la ciudad, sino varios que atendían las demandas eclesiásticas y seglares, tal y como se detecta en la iluminación de códices sevillanos, datados y datables ${ }^{5}$.

Hasta hace poco los únicos datos que conocíamos de la personalidad de Pedro de Toledo fueron, por tanto, aportados por Angulo y Gestoso ${ }^{6}$. A través de ellos se podía observar la personalidad de un artista de gran talla por los encargos que recibió: la iluminación de algunos de los primeros libros de coro a partir de 1434. Sus asientos en los Libros de Fábrica revelan las fiestas más celebradas dentro del calendario litúrgico católico y otras, muy destacadas, en la sede hispa-

2. ANGULO ÍNIGUEZ, D.: "La miniatura en Sevilla. El Maestro de los Cipreses", Archivo Español de Arte 11/III (1928) pp. 65-96; "Libros Corales de la Catedral de Sevilla" en La Catedral de Sevilla, Sevilla, Guadalquivir, 1984, pp. 513-523.

3. DOMÍNGUEZ BORDONA, J.: Exposición de códices miniados españoles. Catálogo, Madrid, Sociedad Española de Amigos del Arte, 1929, pp. 156-160; La Miniatura española, Barcelona, Gustavo Gili, 1930, T. II, pp. 39-40; Manuscritos con pinturas, Madrid, 1938, T. II pp. 148-151; Miniatura. Ars Hispaniae, vol. XVIII, Madrid, Plus Ultra, 1958, pp. 196-197.

4. ÁLVAREZ MÁRQUEZ, C.: "Los artesanos del libro en la catedral hispalense durante el siglo XV", Archivo Hispalense 215 (1987) pp. 3-34. La catedral de Sevilla no cuenta con un verdadero scriptorium, propiciado por el cabildo, hasta 1574, vid. ÁLVAREZ (1987) y ÁLVAREZ MÁRQUEZ, C.: El mundo del libro en la iglesia catedral de Sevilla en el siglo XVI, Sevilla, Diputación Provincial, 1992, pp. 159-162.

5. LAGUNA PAÚL, T.: Postillae in Vetus et Novum Testamentum de Nicolás de Lyra. B.U.S. 332/145-149, Sevilla, Universidad, 1979, p. 61. "Las artes del color" en AA.VV. Andalucía Gótica, Madrid, Encuentro, 1992, p. 79-80. RODRÍGUEZ DÍAZ, E.: "Codicology and Book Production: the making of quires in Castilla manuscripts from XIV and XV (Sevilla and Oviedo)" Seminar in the History of the Book to 1500 (Oxford, 1992) ed. por Anderson-Lovelace (California, USA) en prensa.

6. GESTOSO, J.: Diccionario de artífices que florecieron en Sevilla desde los siglos XIII al XVIII, Sevilla 1899-1908, T. I p. 323. [ANGULO, D.]: "Pedro de Toledo. Miniaturista" en Documentos para la Historia del Arte en Andalucía, Sevilla, Laboratorio de Arte, 1928, T. I p. 143-144. ANGULO (1928). 
lense. Toda esta documentación ha sido revisada por Carmen Álvarez, quien, en 1987, a su vez dio a conocer otros pagos efectuados por los mismos conceptos, entre las mismas fechas, e indicó igualmente uno en 1435 como "escribano de letra gruesa”, que J. Gestoso no reflejó claramente en sus trabajos, y abría un segundo camino en el conocimiento de su personalidad como artífice de libros: escribano e iluminador. Su personalidad como copista de libros fue puesta de manifiesto, por la misma investigadora, en un trabajo publicado en esta revista, al analizar diversos pagos de la mayordomía de Juan Martínez de Vitoria. En él se documentaba el pago de un misal mixto en cuatro cuerpos escrito por Juan García, Francisco Sánchez y Pedro de Toledo, pero la iluminación correspondía únicamente a este último. Se aportaban otros aspectos a destacar como la noticia de un viaje a Roma realizada por este iluminador en 1431 y el alquiler de una cámara al cabildo. Junto a éstos otros, no menos interesantes, para el contexto artístico sevillano de la década de 1430: la presencia en la ciudad de Ysambarte y Carli anterior a la conocida por los Libros de Fábrica, una relación de piezas de plata, desaparecidas,... asi como la existencia de libros corales concluidos en $1433{ }^{7}$. Estos últimos perfectamente asentados en el apéndice documental que recoge el estudio, lo cual demuestra que la confección de libros corales para la catedral de Sevilla es también anterior a lo que se pensaba hasta ahora.

Las fuentes indicaban la confección de un misal rico, pero el inventario de bienes del mayordomo Juan Martínez de Vitoria precisaba más: "para el altar nuevo de la iglesia". Este misal fue localizado y estudiado paleográfica y codicológicamente por Elena Rodríguez Díaz ${ }^{8}$. Su estudio es importante para la historia del libro manuscrito en Sevilla por tratarse de una obra segura de Pedro de Toledo en la que se han analizado todos sus aspectos: primero en su factura material y, ahora, su ornamentación que ha sido, asi mismo, cotejada con otros manuscritos sevillanos del siglo XV. Ésto ha permitido establecer los primeros acercamientos al sistema de trabajo y evolución estilística de la miniatura sevilla-

7. ÁlVAREZ, C. (1987) pp. 13-14. ÁLVAREZ MÁRQUEZ, C.: "Notas para la Historia de la catedral de Sevilla en el siglo XV", Laboratorio de Arte 3 (1990) p. 15-17, y 23.

8. El Misal se conserva en la Biblioteca Capitular y Colombina de Sevilla y estaba catalogado por J. JANINI en Manuscritos litúrgicos de las Bibliotecas de España. Castilla y Navarra (Burgos, 1977) n. 321 , p. 268. Recientemente ha sido mostrado en dos exposiciones: Las Joyas de la Colombina. Las lecturas de Hernando Colón (Sevilla, Consejería de Cultura, 1989) n.. 61 pp. 88-89; Magna Hispalensis. El Universo de una Iglesia (Sevilla, Comisaría de la ciudad para la EXPO'92, 1992) n.o 117, pp. 279 y 281. Sin embargo en la última no se recogieron las últimas investigaciones que cambiaban, evidentemente, la cronología de los cuatro volúmenes y publicadas por E. RODRÍGUEZ DÍAZ: "Un misal hispalense del siglo XV. Estudio codicológico y paleográfico" Historia, Instituciones, Documentos 17 (1990) pp. 195-235. 
na de esta centuria a partir de códices, datados y datables, que indicaban fechas seguras ${ }^{9}$ en la evolución cronológica.

Pedro de Toledo es, por tanto, un artífice en el que concurren los oficios de escritor y miniaturista. Además ambas facetas pueden constatarse en una cuarta parte de los copistas que trabajan en Sevilla a lo largo del siglo XV ${ }^{10}$ y hacen suponer la existencia de talleres especializados en las distintas facetas de la confección de libros en esta ciudad. No se conocen, aún, sus orígenes, pero desde 1430 y hasta 1436 realiza obras, documentadas, para la catedral de Sevilla donde comenzó a trabajar dos años antes. En esta fecha debió iniciarse el Misal Mixto en cuatro volúmenes que terminó de abonársele el 26 de marzo de 1433 y de cuya iluminación es autor ${ }^{11}$. Por motivos, hasta ahora desconocidos, abandonó durante un tiempo la confección del misal, al efectuar un viaje a Roma en 1431. Durante un año no se constata su presencia en Sevilla: quedó interrumpida la iluminación del misal aunque no su escritura, en cuya tarea fue sustituido por Francisco Sánchez "el viejo". En este viaje entraría, sin duda, en contacto y entablaría relaciones con pintores e iluminadores italianos que afianzaron algunos aspectos de su personalidad artística. Una vez concluido el misal comenzaría, por encargo de la catedral, la confección de algunos corales cuyos pagos se efectúan según los Libros de Fábrica en 1434, pero el testamento de Juan Martínez de Vitoria indica que, en diciembre de 1433, ya "estaba pagado de todas las letras que había iluminado en el primer cuerpo de los citados santorales" 12. Además en el inventario de bienes del mismo mayordomo quedan asentados un coral, ya encuadernado, que posiblemente sea el mencionado y otros cuadernillos para oficios cantorales, sin encuadernar, que pudieran corresponder a algunos de los abonados en la primavera de 1434. Durante los años 1430-1431 y 1433 tuvo alquilada una "cámara" al cabildo cuya ubicación no conocemos pero sí hay que pensar en un recinto no ajeno a la misma catedral o bien en una casa cercana ${ }^{13}$. Desde entonces es un artista constante en los pagos catedralicios hasta, de momento, 1436.

9. LAGUNA PAUL, T.: "Consideraciones sobre la miniatura sevillana del siglo XV" en Coloquio: Flanders and the European Perspective (Lovaina, Universidad Católica, septiembre 1993) en prensa.

10. PARDO, M.L. y RODRÍGUEZ, E.: "La producción libraria sevillana durante el siglo XV: Artesanos y manuscritos", Comunicación presentada al X Coloquio del Comite Internacional de Paleografia Latina (Erice, Octubre 1993) en prensa.

11. RODRÍGUEZ, E. (1990) p. 228.

12. ÁLVAREZ, C. (1990) pp. 15,23 y 30.

13. El alquiler de locales o casas por parte del cabildo catedral a los artistas que trabajaban o realizaban obras para él debió ser una práctica corriente. A este respecto cabe citar que en 1497 la viuda de Mercadante de Bretaña aun mantenía una casa alquilada a la sede hispalense. Para el estracto del documento Vid. BONO, J. y UNGUETTI, C.: Los protocolos sevillanos de la época del descubrimiento Sevilla, Colegio Notarial, 1986, p. 74, n. 94.43. 
El volumen de su obra documentada hace suponer que estaría auxiliado por un taller cuyos miembros pudieron realizar las partes secundarias de la decoración, pero sólo tenemos constancia de un compañero encuadernador. Una pequeña nota autógrafa, situada en el último folio vuelto del cuadernillo 8 del vol. I del misal, escrita en bastarda dice: "Destas tres fojas me deven de la escritura e de iluminación" y fue escrito, como ha demostrado E. Rodríguez, por Pedro de Toledo ${ }^{14}$. Por lo tanto la existencia de un taller a cargo de Pedro de Toledo es algo únicamente fundamentado, de momento, en la práctica conocida en otros talleres del siglo XV y la gran cantidad de obras que ilumina y escribe por encargo del cabildo catedral: desde 1430 hasta 1436 se le abonan más de 16.647 maravedíes, según la documentación conocida hasta el momento. Además la preparación material del misal no revela avisos para la iluminación aunque, éstos, pudieran encontrarse debajo de las miniaturas,.

\section{EL ENCARGO DEL MISAL MIXTO}

Los años que trabaja Pedro de Toledo para la catedral hispalense coinciden con una época de febril actividad artística en una sede que necesita y desea nuevos libros litúrgicos, solemnes, para el templo que está construyéndose. Dentro de este contexto hay que situar los encargos que este artista recibe y en especial este misal.

Durante más de dos siglos, desde la conquista de la ciudad, el culto se había realizado en la antigua mezquita almohade adaptada para la celebración del culto cristiano, que se pobló de altares y pinturas, desaparecidas en su gran mayoría. Los libros litúrgicos de este momento debieron ser obras adaptadas en su mayor parte, porque al analizar los conservados, las investigaciones que se están llevando a cabo ${ }^{15}$, nos dicen que son sacramentarios toledanos convertidos a la liturgia hispalense. No es hasta fines del s. XIV, de momento, cuando se encuentra un códice realizado en esta ciudad para la catedral de Sevilla; teniendo siempre en cuenta que nos referimos, lógicamente, a obras conservadas. Se trata del Sacramentario escrito por fray Iohan y concluido el 27 de febrero de 1393, aproximadamente un año antes de que tomara posesión de la sede hispalense D. Gonzalo de Mena, y posiblemente el último que se realiza para el antiguo templo. El estilo de sus letras decoradas y los elementos zoomorfos del Te Igitur tienden a

14. RODRÍGUEZ, E. (1990) not. 56, p. 229.

15. Agradezco a D. Fco. Javier Vázquez las referencias sobre los aspectos codicológicos y paleográficos aportadas sobre la confección de algunos sacramentarios de los siglos XIII y XIV conservados en la Biblioteca Capitular de la Catedral de Sevilla. 
recrear modelos de ascendencia anteriores, retardatarios ${ }^{16}$. Destaca un predominio de formas fitomorfas con tallos terminados en tres frutos redondos de intenso color naranja, hojas cortas con terminaciones muy pronunciadas, y también la simetría compositiva de la decoración vegetal, más evidente aún en los fondos geométricos con inserciones de rosetas y en los sencillos entrelazos.

A la muerte de este prelado, el cabildo eclesiástico sevillano entró en un período de sede vacante pero, a los pocos meses, tomó una de las decisiones más transcendentales para el desarrollo del gótico hispalense: la construcción de una nueva catedral. Su fábrica reunió en la ciudad a un buen número de arquitectos y escultores, nacionales y extranjeros, de reconocido prestigio que trajeron las tendencias del gótico de 1400 a la ciudad. Esta decisión tan importante hay que entenderla en el contexto de un cabildo económicamente muy fuerte, por las propiedades territoriales que tiene acumuladas en este momento: un rico patrimonio rural bien administrado por los prelados sevillanos. La fortaleza del cabildo les llevó a tomar acuerdos transcendentales e, incluso conscientes de su poder, a oponerse a algunos arzobispos, impuestos y no residentes, como D. Diego de Anaya. Un cabildo fuerte y rico, con voluntad de cambio, que, como ha señalado recientemente J. Sánchez Herrero, estaba capacitado para enfrentarse a cualquiera y en primer lugar a su arzobispo, como así ocurrió repetidamente en estas fechas ${ }^{17}$. D. Alonso de Ejea, que se hace cargo de la sede a mediados de 1403, ya fue enterrado en una de las capillas más antiguas, posiblemente la primera terminada, la de San Laureano en 1417.

La época del arzobispo D.Diego de Anaya coincide con el momento en que están documentados los primeros artistas extranjeros en Sevilla: Ysambarte (1433-1434) y Carli (1435-1449) como maestros de obras en la catedral; dos artistas franceses realizan los tres primeros volúmenes de las Postillae in Vetus et Novum Testamentum encargadas por Per Afán de Ribera ${ }^{18}$. Años más tarde, el florentino Sansone Delli parece, pero no es seguro ${ }^{19}$, que estuvo al servicio de la corte en 1446. Diego de Anaya fue un prelado inserto en la convulsión política

16. B.C.C. 85-8-8. Catalogado por JANINI, J. (1977) n. ${ }^{\circ}$ 322. Para la iluminación Vid. LAGUNA, T. (1993)

17. Para los aspectos económicos del cabildo hispalense: MONTES ROMERO-CAMACHO, Is.: Propiedad y explotación de la tierra en la Sevilla de la Baja Edad Media Sevilla 1989. Sobre los prelados sevillanos de estas fechas: ALONSO MORGADO, J.: Prelados sevillanos Sevilla 1899. 1904; SÁNCHEZ HERRERO, J.: "Sevilla medieval. siglos XIII-XV" en Historia de la Iglesia de Sevilla Sevilla, Rodríguez Castillejo, 1992. pp. 211-219. LAGUNA, T. Andalucía Gótica p. 44-47, 79-80.

18. LAGUNA, T. (1979). Para el análisis codicológico de ellos vid. RODRÍGUEZ,E. "Libro y Humanismo en la Sevilla del siglo XV" Historia, Instituciones, Documentos 20 (1993), pp. 475-494.

19. SILVA MAROTO,M.P.: "Nuevos datos para la biografía de Sansón Florentino" Archivo español de Arte XLIV (1971) 155-156. 
provocada por el gran Cisma: viajes y relaciones que le debieron convertir en un hombre internacional con los ojos abiertos a las nuevas corrientes artísticas ${ }^{20}$, pero se vió enfrentado al rey, de cuyos hijos había sido preceptor, al papa a quien había apoyado, y a su cabildo. Durante su mandato (1418-1431 y 1435-1437) los vicarios fueron los que verdaderamente gobernaron la sede hispalense debido a sus reiteradas ausencias y a la tardanza en entrar en Sevilla, que se llevó a cabo el 13 de diciembre de 1427. Tres años más tarde las continuas quejas del cabildo ante Martín V motivan su marcha y la llegada de un administrador apostólico a Sevilla: el jerónimo Lope de Olmedo.

En estos años debió plantearse la necesidad de encargar un Misal Mixto o plenario que recogiera el culto de la sede hispalense, rico, "para el altar nuevo de la iglesia" que es sin duda el "libro mixto que fizo Pedro de Toledo", cuyos pagos están anotados por el mayordomo de la catedral Juan Martinez de Vitoria. Éste pudo ser un encargo del arzobispo Anaya para congraciarse con el cabildo o, sencillamente, del fuerte y acaudalado cabildo hispalense. Con anterioridad indicamos la importancia de su localización y estudio porque para la miniatura sevillana es la primera obra, conocida y perfectamente documentada, de Pedro de Toledo y presenta unas características estilísticas diferentes en algunos aspectos a las iluminaciones que estudió D. Diego Angulo.

El misal está realizado en cuatro volúmenes, cuyo texto queda dividido por el contenido y ciclo litúrgico correspondiente. La organización originaria de cada uno es: calendario de Sevilla; cómputos reductores de las fiestas móviles del calendario litúrgico [en el vol. I se conservan desde 1428 hasta 1548]; domingos del temporal; orden de la misa, canon y prefacios; santoral hispalense; misas del común de los santos; misas votivas; inicios musicales ${ }^{21}$. En su contenido se

20. Sobre este prelado: MORGADO, J.A.: Episcopologio de la Santa Iglesia Metropolitana de y patriarcal de Sevilla, (Sevilla 1906) pp. 337-344; SÁNCHEZ HERRERO, J. (1992) pp. 214-217. Sobre las empresas artísticas vinculadas a su persona destaca la capilla de los Anaya y su sepulcro en la catedral de Salamanca. Éstas coinciden con la llegada a esta ciudad de los pintores Nicolás Florentino y Dello Delli. Vid. M. GÓMEZ MORENO Catálogo Monumental de España. Provincia de Salamanca Valencia, D.G.B.A., T. I p. 141; DURAN, A. y AINAUD, J. Escultura Gótica. Ars Hispaniae XIII (Madrid, 1958) p.127-128; YARZA, J. "La capilla funeraria hispana en torno a 1400" en La idea y el sentimiento de la muerte en la Historia y en el Arte de la Edad Media (Santiago de Compostela, 1988) pp. 81 ss.

21. B.C.C. $85-8-7,85-8-6,85-8-9$ y 85-8-10. Para el estudio codicológico y paleográfico de cada uno de los cuatro volúmenes: RODRÍGUEZ DÍAZ, E. (1990).

Hay que hacer notar que los prefacios musicales en los misales mixtos o plenarios están situados antes del Te Igitur, por tratarse de notaciones, entonaciones.... anteriores a la consagración. En los Vol. II y III se encuentran en este lugar, también lo debió estar el perdido del vol. IV, pero en el vol. I están situados detrás, lo cual nos hace suponer que la ordenación original de la obra fue cambiada posteriormente, quizá en la reencuadernación del s. XVI, aunque ésto no se detecta en la organización, actual, de los cuadernillos. 
ajusta a los condicionantes de la liturgia hispalense ya que esta sede no adoptó el misal romano hasta 1568 . Su división en cuatro volúmenes obliga a realizar varias páginas de incipit, a repetir las oraciones y Canon de la Misa, las misas del común de los santos, las misas votivas y lós prefacios musicales.

El códice tiene una rica ornamentación, de estilo internacional, como corresponde a un misal solemne. Toda su decoración presenta una vinculación con la función litúrgica de la obra, y con la preparación material que tuvo. Por ello su iluminación denota analogías compositivas con otros misales sevillanos realizados años más tarde, aunque éste es el único, de los localizados hasta el momento, en el que se realizaron cuadros o viñetas historiadas. Las letras capitales e iniciales iluminadas de los cuatro volúmenes siguen una clara jerarquía o protocolo a tenor del tamaño y disposición de los marginalia, cuya explicación encontramos en el significado de cada fiesta y que queda reflejado en el pago efectuado. La decoración obedece a unas cláusulas que debieron establecerse a la hora del encargo, a tenor de los datos aportados por el documento de pago ${ }^{22}$. Éste junto con las orlas, marcos y letras decoradas o iluminadas conservadas permite incluso reconstruir, cuando se ha perdido, cual sería su estado originario.

El contrato del misal no se conoce, pero el pago presenta una introducción, previa a los emolumentos, donde se indican aspectos muy interesantes para conocer las condiciones laborales de los distintos oficios y artistas que intervienen en las diversas y sucesivas etapas de la confección del códice: el precio de la escritura, los materiales empleados en la iluminación y, finalmente, la encuadernación. Un libro miniado es un objeto artístico de lujo, caro, cuyo coste depende de distintos aspectos relativos no sólo al pago de sus artífices, sino a los materiales empleados. Los pagos del "Libro misto que fizo Pedro de Toledo" inducen a pensar que pudo realizarse, quizá, un contrato donde se fijarían no sólo las condiciones materiales o laborales sino las características de la obra. El mayordomo de la catedral, Juan Martínez de Vitoria, debió comprometerse a proveer del pergamino necesario, así como un color muy especial: el azul. Por su parte Pedro de Toledo, copista-iluminador, se comprometía a realizar las "letras cabdinales de oro e azul e colores e pone el oro e colores" ${ }^{23}$. Posiblemente también se debió acordar cómo serían iluminadas otras partes del misal pues, más adelante, se indican los precios de las "historias", y se establecen otras letras sin precisar sus características técnicas. En el encargo pudo hacerse alguna referencia a la

22. El documento de pago está citado por C. ÁLVAREZ (1990) p. 15 y E. RODRÍGUEZ (1990) pp. 214-216, por su importancia ha sido recogido en nuestro apéndice documental.

23. Durante todo el pago, incluido en el apéndice documental, se indica el precio de la escritu$\mathrm{ra}$, de las distintas letras e incluso del coste de los materiales de la encuadernación, pero en una nota marginal del f. $13 \mathrm{v}$ se indica "costó el quaderno $\mathrm{L}$ mrs." que evidentemente es distinta al precio que se contempla al comienzo "e escrive todo sisterno por çiento mrs. syn las letras cardinales" (f.11v). 
encuadernación, cuyos materiales y factura se asientan independientemente a Pedro de Toledo quien, por otros documentos, sabemos que tenía "un conpannero enquadernador" ${ }^{24}$ a quien en algunas ocasiones se le dieron cantidades a cuenta.

El coste de la iluminación, por otros estudios publicados, podía variar mucho según los materiales empleados, la persona que los proveyera, la pureza de los colores, y la proporción o cantidad de color u oro empleado en cada letra e iluminación, lo cual también oscila dentro de un mismo códice por los diferentes tamaños de las letras. En este sentido es importante resaltar que el azul y el oro, los materiales más costosos, son comprometidos directamente por ambas partes. Las distintas cantidades y proporciones, junto con otros colores, es lo que establece cinco diferencias de precio en las letras, al indicarse cuatro más baratas que las "cabdinales", cuyo coste es proporcional al tamaño y materiales empleados, según se detecta en el estudio de la obra. Letras de distinto carácter con un precio descendiente y proporcional de mayor a menor: "letras cabdinales" a 60 mrs.; "letras de los ofiçios de las dominicas" a $15 \mathrm{mrs}$, lo cual supone una cuarta parte de la anterior; "letras de los ofiçios de las ferias e las fiestas" a 3 mrs., una quinta parte menos; "letras de las oraçiones e evangelios e epístolas" a $1 \mathrm{mrs}$. equivalen a una tercera parte en relación con la precedente; "las letras de los responsos e aleluyas" tienen un precio intermedio respecto a las dos últimas pues-son abonadas a 15 dineros, cuya equivalencia en maravedis es $1,5^{25}$.

Respecto a la compra del pergamino, la práctica más usual en Sevilla durante el s. XV, a tenor de los últimos estudios, es la provisión de este material por los escribanos quienes incluso podrían adquirirlos ya formados a los pergamineros (PARDO y RODRÍGUEZ, 1993). Hecho que también se constata en el s. XVI (ÁLVAREZ, C. 1992, p. 153 y 154).

Sin embargo en época del mayordomo Martínez de Vitoria, las anotaciones de los pagos del misal y una deuda que este mismo reconoce con el pergaminero inducen a pensar en excepciones a la regla general, como puede observarse en la lectura del testamento publicada por C. ÁLVAREZ (1990) p. 23.

24. De momento se desconoce quién encuadernó las obras, por ello nos referimos a éste tal como aparece citado en el testamento Vid. ÁLVAREZ, C. (1990) p. 23.

La encuademación original, que no se conserva, pudo ser parecida a la de otro Misal Mixto fechado h. 1450 (B.C.C. 84-1-1) a tenor de su descripción en el inventario del mayordomo: "[93] Item un libro que es terçero cuerpo del Mixto del Altar nueuo de la Iglesia en forrado de damasquin verde nueuo e sus guarnimientos dorados e sus registros de sirgo metido en una talega de cannamazo". ÁLVAREZ,C. (1990), p. 30. Tampoco ha llegado hasta nuestros días la cubierta descrita en el inventario de 1595, recogida por C. ÁLVAREZ (1992) p. 98. mental.

25. ÁLVAREZ, C. (1990) p. 15 y RODRÍGUEZ, E. (1990) pp. 215-216. Vid. Apendice docu-

Sobre las equivalencias monetarias: O. GIL FARRES: Historia de la moneda española Madrid 1959; pero debido a sus oscilaciones agradezco a A. Collantes de Terán las noticias aportadas respecto a los cambios y equivalencias en Sevilla durante los años de la confección del Misal. 
Esta clasificación de las letras está directamente relacionada con las distintas partes textuales del misal. Obedece a un código litúrgico, claro y jerarquizado, que tiene su explicación en la Historia de la Liturgia y en los usos de la sede hispalense. Éstos aspectos también se tuvieron, por tanto, en cuenta a la hora del encargo, puesto que la iluminación tiene como función resaltar, destacar y marcar visualmente el contenido textual de la obra cuya tipificación conocían, lógicamente, los artistas y tenían en cuenta a la hora de planificar su trabajo en los talleres. Las especificaciones del pago son, como en otros contratos de iluminación publicados, bastante generales y tampoco se menciona específicamente el precio de las orlas, antenas y demás decoraciones marginales. Éstas partes, según se viene indicando en distintos estudios, eran las primeras que se miniaban en los talleres y su preparación competía, al parecer, a los ayudantes ${ }^{26}$. Por ello si la capital subraya visualmente el texto y es lo que especifica la documentación, en los distintos contratos y pagos conocidos, es porque, posiblemente, su coste comprende el de la marginalia que la acompaña, al menos en este misal mixto. De esta forma pueden verse relaciones con el sistema de trabajo de la pintura monumental y de tabla, muy señaladas en otros estudios respecto al tratamiento compositivo de las escenas, en tanto en cuanto al hablar de los costes de iluminación se estarían pagando centímetros pictóricos sobre pergamino.

El Misal Mixto es un libro propio de la liturgia hispánica o mozárabe que surgió de la necesidad de refundir los múltiples y variados libros de culto en uno sólo o en unos pocos libros plenarios. Estas obras denominadas misticus, pro mixtus, contenían casi todos los libros necesarios para la celebración del oficio catedral festivo y de la misa. Su contenido solía repartirse en cuatro volúmenes, aunque también se conocen obras en dos o en un único volumen. Esta denominación quedó vinculada a las obras de la liturgia hispánica a partir de la restauración del cardenal Cisneros y la publicación del Missale mixtum secundum regulam beati Isidori dictum mozarabus en 1500 . Su nombre puede inducir a errores cuando significa solamente misal plenario cuyo contenido, divisiones, misas y oficios queda perfectamente clara en la bibliografía especializada ${ }^{27}$. Contiene, por tanto, todas las partes de la misa, recitadas por el sacerdote, así como las

26. Sobre estos aspectos puede consultarse entre otros J. J. ALEXANDER: Medieval Illuminators ant their methods of work, New Haven and London, Yale U.Press, 1992, pp. 26, 36-51, 53, 180181. Así mismo, éste publica dos contratos de misales de 1399 y 1448 , donde no se indica pormenorizadamente el carácter de cada letra, pero sí los rasgos técnicos de las más destacadas, que son semejantes al preámbulo de nuestro apéndice documental.

27. Sobre estos aspectos del origen y composición de estos códices litúrgicos y sus diferencias con otros misales puede consultarse entre otros: CABROL y LECLERQ Dictionaire de archeologie chretienne T. XI/2 (1943) pp. 1431-1493, XII/1 (1935) pp. 406-407. FRANQUESA, A.M. "Liturgia hispánica" en Diccionario de Historia Eclesiástica de España Madrid, C.S.I.C., (1972) vol. II pp. 1309-1310. 
lecturas y todas las piezas del canto. Lógicamente estos misales mixtos se atienen textualmente a normas litúrgicas que obedecen al ámbito del derecho canónico común, medieval, y el privado. La España bajo medieval, aunque desarrollara también ceremonias y ritos propios, se hallaba bajo la misma disciplina que la Iglesia universal. Ésta, aparte de establecer unas normas estrictamente litúrgicas, había promulgado unas determinadas leyes jurídicas en su ordenamiento, que regulaban las fiestas de guardar para todos los cristianos, como son el Decreto de Graciano (h.1140), Decretales de Gregorio IX (1234), el Liber Sextus de Bonifacio VIII (1298) que fueron codificados por las Clementinas o Libro Septimo, y otros textos como las Constituciones del Concilio de Vienne (1311-1312). A grandes rasgos este Derecho Común, canónico, ofrece una relación de las festividades que la Iglesia prevee para los fieles universales ${ }^{28}$, mientras que el derecho canónico particular, regulado por los sínodos diocesanos, indica el diverso tratamiento que otras fiestas tienen dentro de cada diócesis. A éste derecho común y particular es, por tanto, al que hay que acudir para observar las diferencias que presentan los calendarios, recogidos en códices litúrgicos, de diversas sedes y, lógicamente, a los distintos tratamientos decorativos que pueden observarse en la composición de la iluminación en los códices litúrgicos. Ésta señala, visual y estéticamente, las partes textuales ajustándose a unas reglas establecidas, reguladas con anterioridad, conocidas por los talleres que se dedicaban a la confección libros miniados, y señaladas en los pagos de nuestro misal: una jerarquización iconográfico-iconológica.

La comprensión de estos aspectos es lo que permite localizar perfectamente cada uno de los pagos, comprender sus diferencias de tamaño o de los marginalia... porque el tratamiento estilístico y estético, que realizó Pedro de Toledo, es unitario en el conjunto de todo el misal. Así se entienden, incluso, las diferencias crematísticas entre las historias, perdidas, del Te igitur.

28. El Decreto de Graciano C.15 q.4 c1-3 indica las siguientes fiestas que tienen un tratamiento dominical: todos los domingos del año y el día de Navidad, Teofanía [Epifanía], Purificación de Santa María, Pascua con toda la semana que le sigue, los tres días de Rogaciones, Ascensión, Pentecostés, San Juan Bautista, los doce apóstoles y en especial San Pedro y San Pablo, San Lorenzo, Asunción de Santa María, Natividad de María, dedicación de cada iglesia, San Miguel Arcangel, dedicación de cada oratorio, Todos Santos y San Martín. A su vez admite que los obispos instituyan otras festividades a escala local. GARCÍA y GARCÍA A.: "Religiosidad popular y festividades en el occidente peninsular (s. XIII-XVI)" en Colloque franco-espagnol: Fêtes et liturgie (Casa de Velázquez 12/14 diciembre 1985) Madrid, Univ. Complutense, 1988 pp. 36-38. Para las fiestas en Sevilla puede consultarse SANCHEZ HERRERO, J.: "La religiosidad popular en la Baja Edad Media Andaluza" en Homenaje a Alfonso Trujillo, Tenerife, A.C.T., 1982 pp. 289-320; "Algunos elementos de la religiosidad cristiana popular andaluza durante la Edad Media" en La religiosidad popular. I Antropología e Historia, Sevilla, Fundación A. Machado- Ed. Antrhropos, 1989 pp. 276-298. 


\section{ORGANIZACIÓN Y CARACTERES DE LA DECORACIÓN}

\section{1. "Las estorias grandes que fizo en el Te Igitur"}

Los cuadernillos centrales de los códices presentan, como es usual en los misales, las oraciones que conforman la santa misa: oraciones, prefacios y canon. De éstas, es en el canon donde se concentra la decoración más destacada: una escena, "historia", donde se representa, a página llena o en una viñeta, una crucifixión, un pantocrator o incluso ambas. A la vista del celebrante ofrecen una doble página abierta, de carácter solemne, en el momento que eleva los brazos y dice: Te igitur, clementissime... .

El documento de pago especifica dos cantidades diferentes en concepto de las "estorias grandes que fizo en el Te Igitur": $250 \mathrm{mrs}$. y $300 \mathrm{mrs}$. para los volúmenes primero y segundo respectivamente ${ }^{29}$. Nada se indica de los dos restantes porque el mayordono le fue dando a Pedro de Toledo cantidades a cuenta desde julio de 1430, pero los cuatro volumenes tuvieron "historias" que representaban una crucifixión, a tenor de los restos visibles del vástago de una cruz en el segundo volumen. No obstante el tratamiento y organización originaria no fue el mismo.

En el segundo volumen la escena se sitúa en el folio vuelto de la doble página, ocupando nueve renglones, encima de las oraciones de la aspersión del agua bendita, que el celebrante realiza en las misas solemnes dominicales antes de la misa, mientras que en el recto se ubica la oración del canon. En el primero quedan restos, encima del Te Igitur, de un marco de color rojo, de once renglones de alto, que debió tener otra crucifixión ${ }^{30}$. Las diferentes dimensiones de estas dos escenas, mutiladas, no tienen correspondencia con los pagos efectuados por ellas, al ser imposible apreciar el tratatamiento que les confirió Pedro de Toledo. Sin embargo la riqueza de los marginalia es bastante superior en el segundo volumen y sin duda alguna las variaciones crematísticas obedecen a los materiales empleados y al diseño de la orla. Por ello, posiblemente, en el pago de estas "historias" también se incluyeran los marginalia y de ahí los distintos pagos. La orla del primer volumen es de tipo parisino y necesita mucho menos oro y pigmentos en su confección (lám. 1), mientras que la del segundo está poblada de ramas auríferas que llenan por completo los márgenes y centran

29. ÁlVAREZ, C. (1990) p. 16. RODRÍGUEZ, E. (1990) p. 209. Vid Apéndice documental fol. 11v.

30. Vol. II= B.C.C. $85-8-6 \mathrm{c} 20 \mathrm{f} .4 \mathrm{v}$ el tamaño aproximado de la escena sería $135 \times 180 \mathrm{~mm}$. En el Vol. I= B.C.C. $85-8-7 \mathrm{cl} 2 \mathrm{f} .1 \mathrm{r}$ el tamaño aproximado sería 165 x $180 \mathrm{~mm}$.. El Vol. III= B.C.C. $85-$ $8-9 \mathrm{c} 15$ ha perdido el folio del Asperi... donde se encontraría la escena y al Vol. IV= B.C.C. $85-8-10$ le falta todo el canon. 
cuatro escudos que representan: una cruz de madera con tres clavos, sobre un montículo, en campo dorado. Las "armas Christi" (láms. 2 y 3).

Estos elementos heráldicos, del segundo tomo, deben estar vinculados al comandatario del misal, al contexto en que éste fue encargado y a los cambios de prelados en Sevilla durante su confección. Los folios del Te Igitur en los misales suelen presentar en la parte inferior de la justificación una cruz de oro, aunque no se insertan en un espacio de carácter heráldico sino en campo libre. Posiblemente cuando este folio fue iluminado, antes de julio de 1430, los campos heráldicos irían destinados a recoger las armas del obispo o las del cabildo, pero los conflictos existentes entre el cabildo hispalense y D. Diego de Anaya le obligaron a abandonar la sede cuando el papa Martín V nombró prelado apostólico de Sevilla a fray Lope de Olmedo, quien estaba en ya en esta ciudad el 31-9-1431. En mayo del mismo año, Pedro de Toledo se va a Roma y nuevamente percibe pagos continuados desde diciembre de 1432 hasta marzo de 1433 cuando, en enero del último año, ya había sido nombrado obispo D. Juan de Cerezuela, quien posiblemente utilizó este misal en las misas solemnes. Por ello la inclusión de estas "armas Christi" pudo ser una solución de compromiso vinculada, lógicamente, al carácter iconográfico del canon de la misa y adoptada por el taller bajo las indicaciones del mayordomo.

\section{2. "Letras cabdinales. Letras de los ofiçios de las dominicas. Letras de los ofiçios de las ferias e de las fiestas"}

Las partes textuales del misal tenían originariamente cerca de 450 letras miniadas con oro y colores de las que subsisten $310^{31}$. Su tamaño depende de la importancia que cada fiesta tiene y de su rito que queda reflejado en los tres calendarios conservados.

31. El misal tiene bastante mutilada su decoración. Han desaparecido la totalidad de sus historias y el número de letras originarias es difícil de indicar con exactitud por la pérdida de cuadernillos. Puede afirmarse, por la importancia de la fiesta o la falta de misas determinadas, la falta de 78 seguras más otras fundamentalmente de cuarta, quinta y sexta dignidad, cuyo numero preciso no podemos determinar por la presencia, en numerosas ocasiones, de rúbricas aludiendo a fiestas de santos determinados que en este momento no debían tener misa propia en Sevilla, y aparecen en misales de mediados del s. XV.

- Para el primer volumen (85-8-7) Pedro de Toledo recibió solamente por la decoración de 116 letras y dos historia la cantidad de 2.043 maravedís. No obstante sólo se conservan 114 letras y la historia ha desaparecido en su totalidad.

- En el segundo cuerpo (85-8-6) realizó 84 letras y una historia recibiendo únicamente por la decoración 1.295 maravedís. Actualmente quedan sólo 67 letras.

- En el tercer volumen (85-8-9) realizó 99 letras de las que faltan 22. Este volumen como lo escribe entero no muestra una diferenciación en los pagos: por ello recibe en concepto de escritura e 
Todas las letras debieron realizarse con plantillas en espacios dejados ex profeso a la izquierda y quizá marcados con letras de aviso, que quedaron ocultas una vez realizadas ${ }^{32}$. Las capitales se sitúan, por tanto, a la izquierda de la justificación, quedan encajadas al estilo gótico y en algunos casos se observan unas líneas realizadas, cuando se copió el texto ${ }^{33}$, que permitirían acoplar las plantillas. La decoración de la ornamentación marginal tampoco presenta rótulos de aviso ${ }^{34}$ y en su técnica puede observarse, por el deterioro de algunas orlas francesas, un ligero dibujo preliminar y punteado que debió servir de guía a los iluminadores para trazar las puntiagudas hojas de vid góticas. El cuerpo de estas letras es siempre modelado y realizado con pintura cubriente, azul o rosa, de un sólo color matizado y una decoración que presenta bien ondas nebulosas góticas, elementos ondulados o diversas formas rectilíneas (aspas recruzadas y trastes o eses geométricas) alternantes y separadas por líneas sencillas o dobles. En otras ocasiones el cuerpo de la inicial está decorado con media hoja gótica. El carácter de los marginalia obedece a las mismas corrientes estilísticas que las iniciales, pero su disposición en la justificación del folio y tamaño, depende del texto al que acompaña.

Las capitales más destacadas por su tamaño corresponden a las fiestas más importantes, junto con el Te Igitur. Son letras de más de cinco puntos de altura ${ }^{35}$, pero no aparecen siempre en folios con los cuatro márgenes decorados (lám. 4).

iluminación 4.203 maravedís. Sin embargo por los cuadernillos que escribió y el numero de capitales conservadas, y las que indudablemente ha perdido, nos hacen suponer que percibiría en concepto de iluminación entre 1500 y $1600 \mathrm{mrs}$.

- En el cuarto volumen (85-8-10) realiza igualmente la decoración, por la que percibió 1600 mrs., pero no sabemos con exactitud el número de letras originales por la pérdida de los cuadernillos y el desorden en el que se encuentran. Tiene cortadas 15 y sólo quedan 52 .

32. No se observa ninguna anotación que denote letras de aviso, ni bajo la luz de infrarrojos, debido a que la técnica empleada en su confección empasta mucho el color que queda opaco y denso. La localización de letras de aviso en otros misales sevillanos de la Biblioteca Capitular es dificultosa: generalmente sólo se percibe en las letras de filigrana, que no existen en este misal de Pedro de Toledo, con una minúscula muy cerca del cuerpo de la inicial.

33. Son evidentes, por ejemplo, en la capital I del santoral hispalense correspondiente a San Basilidis, Cirini y Naboris (85-8-9 cl9 f.4v) realizado íntegramente, texto e iluminación, por Pedro de Toledo.

34. Sólo se ha percibido un aviso para la rúbrica de unos prefacios musicales $(85-8-6 \mathrm{c} .16 \mathrm{f} .7 \mathrm{v})$.

35. El tamaño de todas las letras sigue siempre una proporción cercana al cuadrado aunque, lógicamente, varía dependiendo de la vocal o consonante de que se trate. Esta proporcionalidad se mantiene, sin variaciones destacadas, en los diversos tamaños que puede tener una misma inicial según sea el texto al que acompaña. Por ello, y en aras de una mayor claridad expositiva, es preferible referirse a todas las iniciales por el tamaño que ocupan dentro del folio. Cada punto equivale a una unidad de pautado, que es la distancia proporcional entre renglones. La unidad de pautado predominante en los cuatro volúmenes es $15 \mathrm{~mm}$. o $15,5 \mathrm{~mm}$. que determina 18 renglones pautados en cada folio. Para los aspectos técnicos de la preparación de la página Rodríguez, E. (1990) pp. 209-214. 
Las capitales que inician el comienzo de los diversos oficios dominicales y fiestas asimiladas a dominicas quedan destacadas por orlas que ocupan tres márgenes de la página. Tienen un tamaño un poco menor, cuatro puntos y medio o cinco ${ }^{36}$, pero su ornamentación obedece a las mismas variantes decorativas (lám. 5).

Las letras de las ferias y fiestas son de menor tamaño, cuatro puntos ${ }^{37}$, y presentan los mismos elementos ornamentales, pero van acompañadas de antenas que se prolongan a lo largo de la justificación y ocupan en algunos casos, como máximo, una tercera parte de ésta (lám. 7).

Toda la decoración del Misal Mixto revela unas formas que obedecen a una tradición estilística anterior, vigentes en el período internacional, pero otras son más novedosas. En todas es posible percibir varios grupos de influencias: una parisina y flamenca, otra vinculable a talleres meridionales y finalmente una que, con influencias del internacional sienés y toscano, tiene un carácter netamente "sevillano".

El grupo más numeroso está constituido por una decoración que llena el ojo de las letras, algunas $I$ y el Te igitur, con roleíllos de vides góticas que siguen los modelos desarrollados tanto en los talleres parisinos como por artistas vinculados al ducado de Borgoña y adoptados por numerosos talleres. Este tipo es el predominante, pese al tamaño o enmarque que posean las letras, y en algunos casos tienen motivos centrados en torno a los cuales se dispone la vegetación: formas caprichosas como los entrelazos centrales o los medios lazos que cierran los espacios superior e inferior. El marco, en oro o color, suele ser liso en algunos casos, como cuando se trata de la $L \circ R \circ P$, pero también presenta esquinas que enmarcan el roleillo interno gótico. Pocas veces tienen escotaduras y cuando ésto ocurre, la decoración se destaca sobre un fondo totalmente realizado en oro bruñido. Pueden citarse como variante, de éstas, alguna donde existe un tallo enrollado aunque la hoja de vid llena por completo el espacio circular. Otros fondos de ajedrezados y dameros, cuyos cuadros de color presentan biseladuras blancas, hay que situarlos dentro de la misma influencia (láms. 1, 6 y 7).

En las orlas, que obedecen a esta misma corriente, se observan dos variantes. Cuando ocupan los cuatro márgenes de la página, en los incipit y algunos Te Igitur, muestran grandes nudos cuadrados en los ángulos y una fina hoja de vid que recubre por completo los cuatro márgenes. Las otras son un palo rojo y azul con oro de buen grosor en toda la altura de la columna y de sus ángulos salen tallos de vid que se despliegan y, ocupando casi la totalidad de los márgenes superior e inferior, en algunas ocasiones, presentan aves fantásticas en los extremos que recuerdan otras de la miniatura francesa del tiempo de Jean de Berry. Todas ellas se encuentran, fundamentalmente, en textos de carácter dominical,

36. Aprox. $50 \times 50 \mathrm{~mm}$. y $60 \times 60 \mathrm{~mm}$.

37. Aprox. $45 \times 45 \mathrm{~mm}$. 
pero cuando destacan las ferias, fiestas, misas común de los santos y votivas el palo se adelgaza excesivamente $y$, muestra una pequeña franja de color y una delgada lámina de oro, en relación directa con el menor coste que se indica en el pago.

Otra variación de elementos de la iluminación del trescientos es observable en toda una serie de orlas, antenas y letras capitales que presentan hojas secas y delgadas de vivo colorido, terminadas en agudas prolongaciones lanceoladas semejantes a algunos manuscritos de Aviñón, catalanes y valencianos. Este recuerdo meridional es más evidente en la composición filomorfa de los marginalia, cuyas composiciones semejan algunas del Breviario de Martín de Aragón (B.N.P. Rosthschil,2529 f.152v,351r), o códices realizados en época de Alfonso el Magnánimo como la portada de los Comentarios a los Usatges de Barcelona, iluminada por Bernat Martorell y J.Marquilles en 1448, pero que ya estaban completamente definidos en el Maimónides miniado por Ferrer Bassa en 1348 y conservado en la B.Real de Copenhague. El recuerdo es muy cercano en los cuadros de los incipit, orlas de tres márgenes y antenas, que ocupan un tercio del margen, cuyos elementos compositivos a base de finos palos de color organizan el despliegue de elementos filomorfos estilizados y envolventes que, junto a otros, forman una composición romboidal (lám. 6).

Esta misma corriente se manifiesta en aquellas capitales que presentan en su interior grandes ramas alargadas de vivo colorido y que desde luego no son hojas de acanto. Estas hojas secas realizadas en rosa, minio, oro o azul alternando, están terminadas en tres agudas prolongaciones al igual que algunas antenas y orlas. En otras ocasiones unas hojas más gruesas, pero igualmente agudas en sus extremos, llenan las justificaciones desplegándose de forma caprichosa o incluso poblándose de animales como en el primer domingo de adviento, que inicia el tiempo litúrgico, y se destaca por su importancia textual y composición ornamental (lám. 4).

Existe un grupo poco numeroso de decoraciones marginales con vegetación absolutamente fantástica de palmetas y semipalmetas alargadas en rosa, azul, verde claro, naranja con partes de los tallos y prolongaciones en oro que juegan por los márgenes del folio. Su extravagante movimiento evoca la ornamentación de la miniatura boloñesa del s. XIV pero asimilada, posiblemente, a través de la influencia de las escuelas de Aviñón y la Toscana. Ambos centros recogen la influencia de Bolonia como queda evidente en la decoración filomorfa de manuscritos litúrgicos sieneses de fines del s. XIII de Memmo di Filipuccio, en un leccionario de la Biblioteca Comunal de Siena (h.1290) o incluso en las Constitutio de Lanaiuoli (1292) del Archivo del Estado de Siena ${ }^{38}$. La asimilación de

38. Siena: B.Comunal ms. H.I.10, G.I.2; Archivo Stato ms.Arti 61. Sobre éstos mss. vid. $l l$ gotico a Siena.Catalogo della mostra Siena, Palazzo Publico, 1982 pp. 59-60, 73-74, 157, 160. 
elementos boloñeses se observa en manuscritos toscanos de la primera mitad del s. XIV como el Misal Romano del monasterio de San Pedro el Mayor de Florencia y en un Breviario de la abadía de Vallombrosa ${ }^{39}$. También en España se observa esta asimilación en manuscritos jurídicos catalanes del primer tercio del siglo XIV como los Usatges y Constituciones conservados en la Biblioteca del Vaticano (Cod.Ott.lat. 3058), los del Archivo Municipal de Lérida, y el Libro de Privilegios de Mallorca (1334), o incluso en otros litúrgicos, caso del Breviarum Oscense (Huesca, Ar.Cat. ms.13 f.1r) que tiene las armas del obispo Gastón de Montcada. Estas formas fitomorfas de origen boloñés no son tan perceptibles en obras posteriores a mediados del s. XIV, salvo en la vegetación que aparece en el retrato de autor de la Crónica de los Conqueridores realizada en Aviñon para Juan Fernández de Heredia (B.N.M. ms.10133) ${ }^{40}$ y en este misal sevillano. Serían por tanto elementos fitomorfos que, aunque pertenecientes a una tradicion ornamental anterior al momento en que se compuso este misal, entran dentro de la decoración fantástica que Baltrusaitis analiza en la evolución del rumi gótico ${ }^{41}$ : 'drôlerie', extravagancias propias del gótico del s.XIV y cuyas formas híbridas podemos observar todavía en el primer tercio del cuatrocientos (lám. 2).

La única capital con decoración animada es la correspondiente a la misa mayor de Navidad, aunque es posible que otras, perdidas, de gran importancia festiva y anual lo tuvieran. Del domingo de Pascua, el "maestro de la cuchilla" que cortó el folio, sólo queda, como testigo de su acción, unos pocos centímetros de una, intuimos, de las hojas más decoradas del misal, cuya orla estaba formada por grandes rodeos circundando elementos animados, que pudieran corresponder a diversos santos o profetas ${ }^{42}$. En el inicio del la misa mayor de Navidad (Puer natus est nobis...) la letra destaca sobre un fondo completamente dorado y dentro del ojo de la $P$, centrado por una composición octogonal de hojas delgadas y puntiagudas de vivo color, un animal fantástico en rosa que bien pudiera aludir al Cordero Divino (lám. 5).

Los volúmenes I y III tienen en las partes añadidas al santoral unas capitales distintas. Un marco de oro encuadra el cuerpo de la letra y deja espacio a unas esquinas decoradas con pintura cubriente, azul intenso o carmín, que presentan una fina decoración de hilos blancos retorciéndose y formando composiciones netamente ornamentales. El ojo de éstas queda ocupado por formas filiníceas

39. Florencia Seminario Magg.Cestello cod.235. Vallombrosa Arch.Badia Ms.V.4. Sobre éstos: Codici liturgici miniati dei Benedittini in Toscana Firenze, Centro d'Incontro della Certosa di Firenze, 1982 pp. 141-159, 161-168.

40. DOMÍNGUEZ BORDONA, J.: "Libros miniados en Aviñón para Juan Fernández de Heredia" Museum (1918-1920) pp. 313-327

41. BALTRUSAITIS, J.: La Edad Media fantástica Madrid, Cátedra, 1983 pp. 96-98.

42. B.C.C. 85-8-6, vol. II, c12 fol.1r tiene un pequeño resto de una mano que porta un báculo. 
espirales o romboidales, cuyo motivo interno se distribuye a partir de cuatro hojas astadas que centran un elemento cuadrilobulado en azul. Su decoración recuerda la de algunos manuscritos toscanos contemporáneos como un Salterio Nocturno del monasterio de Monteolivetto (1413-1416) y un Antifonario (14201425) conservado en Chiusi ${ }^{43}$. Las antenas de las letras tienen un tratamiento diferente a las de los inicios musicales del mismo misal y distribuyen la decoración a partir de elementos fitomorfos que desplegándose, sinuosamente, rodean un tallo vegetal o flores de cuatro pétalos de los que surge un fruto agudo. En otros casos, las antenas muestran formas vegetales más delgadas, casi con la misma composición lanceolada que aparece en los códices valencianos y catalanes, pero con las hojas más gruesas y retorcidas. Estas capitales también se dan en códices sevillanos posteriores: quizá sean algo más tardías porque están en partes textuales añadidas ${ }^{44}$ al santoral, pero presentan vínculos compositivos con las $P$ de los prefacios musicales de este mismo misal (lám. 8).

\section{3. "Letras de las oraçiones e evangelios e epístolas"}

Los inicios de las oraciones, evangelios y epístolas están realizados en letras champidas o pequeñas letras de cuerpo dorado sobre un fondo bicolor (rojo y azul) repleto de elementos afiligranados blancos. Situadas, generalmente, en el interior de renglones su tamaño oscila entre un punto y dos puntos y medio ${ }^{45}$. Algunas veces van acompafiadas de unos motivos ornamentales formados por pequeñas antenas de tinta negra terminadas en florecillas trilobuladas. Éstas corresponden a un tipo de inicial secundaria que en algunas ocasiones se emplea para fiestas de poca relevancia y algunos domingos de pentecostés (láms. 3, 4, 6 y 7).

\section{4. “Letras de los responsos e aleluyas" y partes musicales}

En las partes musicales, responsos, aleluyas y prefacios, que preceden al canon, junto con el credo y los glorias se observan tratamientos diferentes en su tamaño, caracter y decoración.

Los responsos, aleluyas, glorias, y partes internas de cada prefacio corresponden a letras que, por acoplarse a la caja de escritura, sobre notación llana de cinco líneas, tienen un tamaño superior a las champidas de las partes textuales ${ }^{46}$.

43. Pistoia Sem.Episc. cod.N f,191r. Chiusi M.Cap. Cattedrale cod.T,f.58r. Sobre éstos: Codici... Toscana 529-535,447-453.

44. RODRÍGUEZ,E. (1990) p.218

45. $20 \times 10 \mathrm{~mm}$., $25 \times 25 \mathrm{~mm}$. y $30 \times 30 \mathrm{~mm}$.

46. Generalmente oscilan entre $55 \times 20 \mathrm{~mm}, 50 \times 15 \mathrm{~mm}$. Las hay también muy pequeñas, un punto de texto, con $13 \times 15 \mathrm{~mm}$. 
Son igualmente letras champidas y deben corresponder a las mencionadas en los pagos en quinto lugar, pues su carácter y dimensiones está en relacción proporcional con las iniciales secundarias de las partes textuales.

No obstante, y aunque rompiendo el esquema trazado en la argumentación de este apartado, se analizan aquí, por tratarse de letras de música, las $P$ de los veinticuatro prefacios musicales, que tenía cada uno de los volúmenes del misal iluminado por Pedro de Toledo. A su vez hay que destacar cómo toda la música está escrita en cuadernillos compuestos por quiniones, mientras en las partes textuales predonima el sesnión y las formas decorativas que presentan, como veremos, sólo tienen relación con las capitales que aparecen en los, mencionados, cuadernillos añadidos de los volumenes I y III. Por su tamaño ${ }^{47}$ debieron abonarse a un precio intermedio entre las dominicas y las fiestas en relación a la importancia de la misa o misas donde fueron entonadas. También pueden detectarse diferencias en el tratamiento ornamental que, en hipótesis, inducirían a pensar remuneraciones diferentes vinculadas a las dominicas y fiestas correspondientes.

En su decoración hay dos tratamientos, aunque todas son letras muy alargadas que, al acoplarse a la música, muestran una proporción arcaizante. Los Glorias y Credos mantienen la tradición de la hoja de vid gótica, pero los prefacios no son tan tradicionales sino más modernos. Estas $P$ se presentan sobre un fondo en oro bruñido, con escotaduras en algunos casos, y su cuerpo se articula en el asta descendente con molduraciones poligonales cimbreadas y trastes, mientras el ojo está bordeado por una línea de pequeñas perlitas. No obstante dos letras mutiladas han conservado una decoración diferente de la $P$ : las bandas de elementos vegetales que rodean el asta descendiente tienen el mismo tratamiento fitomorfo que la que conforman el cuerpo de numerosas letras historiadas en los libros corales ${ }^{48}$. La decoración vegetal que surge de los extremos de estas $P$ se prolonga por el margen con un concepto naturalista, aunque tratado con alegre ingenuosidad: las ramas y tallos, inspirados en hierbas del campo, han sido recreados en el taller del iluminador y adaptados para distribuir los diversos elementos floreados de cuatro pétalos, frutos en baya, ramos filodios y capullos florales de los que surgen unos frutos alargados y punzantes. El espacio, dejado vacío por el ojo de la letra, se llena siempre de sarmientos retorcidos en composiciones centradas con flores abiertas de varios pétalos azul y fucsia, flores cuadrilobuladas, frutos en baya y ramas fitomorfas. Algunas veces, los sarmientos

47. En este caso ocupan, generalmente, dos puntos de las cinco líneas que conforman cada renglón musical. Oscilan entre $280 \times 60 \mathrm{~mm}$. y 73 × 53, aunque el tamaño perdominante es 110 × 80 $\mathrm{mm}$. y $110 \times 60$. Las antenas, que se prolongan por el margen, pueden llegar a ocupar la altura de la justificación.

48. B.C.C. $85-8-7$, c. 14 , fol. 6 b y $85-8-9$, c. 10 , fol. 1 r. 
terminan en pequeñas hojitas que son variantes de las 'vignettes' góticas, pero en otros es una composición triangular que cobija un fruto granado, envuelto por hojas fucsias, de finalidad no sólo decorativa sino, vinculado al texto, aluden a la caridad cristiana abierta a todos ${ }^{49}$. Estas formas fitomorfas y florales presentan antecedentes y sincronías que pueden observarse en la miniatura sienesa y florentina del primer tercio del s.XV, pero su composición es netamente sevillana, como señaló Spalding ${ }^{50}$, relacionada con sedes muy vinculadas a prelados hispalenses -Toledo, Guadalupe y Badajoz- al analizar tres antifonarios, conservados en la Hispanic Society (láms. 9 y 10).

Este tipo ornamental tendrá su propia evolución dentro de la iluminación y pintura mural sevillana del s.XV, lo cual denota la utilización de los mismos motivos por parte de los pintores, como por ejemplo en los paneles decorativos del claustro de los muertos de San Isidoro del Campo ${ }^{51}$. Los elementos compositivos de las $P$ de los prefacios musicales junto con las iniciales de los cuadernillos añadidos son la ornamentación más novedosa del misal en el contexto pictórico sevillano donde se aprecia una continuidad, posterior, con los modelos que Pedro de Toledo empleará en los Libros de Coro catedralicios. Son, hasta la fecha, los modelos más tempranos del gótico internacional sevillano.

\section{CARACTERES ESTILÍSTICOS DE PEDRO DE TOLEDO Y LA PROBLEMÁTICA DE LA INTRODUCCIÓN DEL GÓTICO INTERNACIONAL EN SEVILLA}

Pedro del Toledo es un artista del gótico internacional que en este misal mixto desarrolla, como ha sido analizado, tendencias propias de la miniatura del 1400 , unas recurrentes pero otras contemporáneas a su desarrollo en Siena y Florencia.

La decoración que hemos llamado "sevillana" la realizaba Pedro de Toledo antes de su viaje a Italia en 1431 y aparece en los cuatro volúmenes del misal. Sin embargo, cuando este artista desarrolla más evidentemente la influencia toscana es en los cantorales hispalenses. La iluminación de este misal destaca, a su vez, una continuidad de los modelos internacionales anterior a la, problemática, estancia de Dello Delli ${ }^{52}$ en Sevilla y despierta, nuevamente, interrogantes sobre

49. GNONI, Cr. da esta interpretación en Codici....in Toscana p.326

50. SPALDING, Fr.: "A fragment from a choir book and three related antiphonaires" Notes Hispanic 3 (1943) pp. 58-95; Mudejar ornament in manuscripts (New York,1953) pp.23-29.

51. LAGUNA, T. (1993) en prensa. Sobre S. Isidoro del Campo, D. Pedro Respaldiza está realizando un interesante trabajo y le agradezco el material, inédito, proporcionado.

52. Sobre la pintura gótica internacional sevillana y su problemática Vid. D. ANGULO (1928). VALDIVIESO, E.: Historia de la pintura sevillana, Sevilla, Guadalquivir, 1986, pp. 24-29. SILVA 
el origen, condición y formación de este iluminador: ¿era toledano?, ¿clérigo o seglar?. Su origen no puede afirmarse con seguridad hasta que no se conozcan, mejor, los sistemas de producción libraria de Toledo, y sepamos, al menos, la nómina de sus copistas e iluminadores a principios del siglo $\mathrm{XV}^{53}$.

La miniatura sevillana a partir del segundo tercio del s.XV se mueve dentro de unas corrientes de influencia italiana, florentina y sienesa, cuyas primeras muestras están en las partes musicales del misal de Pedro de Toledo. De haberse conservado las historias del Te Igitur tendríamos su primera obra figurativa, documentada, que hubiera permitido conocer otros rasgos compositivos y figurativos, entre 1428 y 1433, fundamentales para observar mejor sus influencias y contrastar con los libros de coro donde es un iluminador que se mueve dentro de los presupuestos estéticos italianos contemporáneos, que él interpreta de forma personal.

La confección de los libros corales de la catedral hispalense parece remontarse, como ya indicábamos, al menos al año $1433^{54}$. Tal actividad ocupó, durante esta centuria y las siguientes a un buen número de iluminadores, pero un acercamiento a éstos evidencia cambios y remodelaciones a lo largo de los siglos para adaptarse a nuevos usos y costumbres. En ellos se encuentran, aproximadamente, unas 150 letras historiadas realizadas en el siglo XV, aparte de orlas y letras miniadas destacadas, que repartidas en distintos libros deben corresponder a los pagos efectuados a Pedro de Toledo, Antón Sánchez, Francisco Sánchez, Diego Fernández de los Pilares, Nicolás Gómez, Juan, Nuño García, Juan Sánchez, Antón Rodríguez y Lucián Rodríguez ${ }^{55}$. Su identificación plantea serías dificultades: pagos reiterados por un mismo concepto a varias personas y no conservan actualmente la composición originaria que permitiría identificar, fehacientemente, los asientos.

El grupo de 83 letras historiadas analizadas por D.Angulo en los corales responde a unas características bastante homogéneas en el tratamiento compositi-

MAROTO,M.P.: "Nuevos datos para la biografía de Sansón Florentino" Archivo español de Arte XLIV (1971) pp. 155-164. LAGUNA, T.: "Las artes del Color" Andalucia Gótica pp. 79-89.

53. La tesis doctoral de L. BOSH Manuscripts illumination in Toledo (1446-1495). The liturgical Books MIchigan, U.M.I., 19852 vols. no analiza la primera mitad del s. XV.

54. En el inventario de los bienes de Juan Martínez de Vitoria, publicado por C. ÁLVAREZ (1990) pp. 30-31, quedan anotados diversos cuadernillos sin encuadernar que, sin duda, indican, encargos anteriores por parte del cabildo que comprenden las fiestas más destacadas junto a otras del Común de los Santos. Son los asientos n. $94,95,96,97,98,100,102,117,118,119$. Otros estarían ya encuadernados como el recogido con el n. ${ }^{9} 102$ : "Item un libro sanctoral nueuo de cantoría que comiença In Vincula Sancti Petri fasta el fin e tiene más las Cinco Estorias e más el Común del Tiempo de la resurreç̧ion, enquadernado en tablas de cuero blanco e clauos".

55. GESTOSO, J. Diccionario... T. I pp. 211, 215, 217, 319, 320, 322. GESTOSO, J. Sevilla Monumental... T. II pp. 248-249. ÁLVAREZ, C. (1987) pp. 9-10, 4-7, $13-20$ y 35. ÁLVAREZ, C. (1990) pp. 15-17.56. 
vo de orlas y capitales. En los marginalia predomina un empleo del oro en besantes y centros de flores trilobuladas. También hay grandes hojas, que se estiran a lo largo de la hoja o se enroscan formando un roleo, con una penca interna que organiza la composición y centra diversas formas vegetales: flores de larga semilla retorcida, botones de flores y frutos granados, semejantes a los que aparecen en los añadidos del misal mixto. El cuerpo de la capital destaca sobre un recuadro de oro bruñido, que puede presentar escotaduras, y articula las escenas de las historias y figuras desarrolladas en paisajes abiertos, casi siempre llanos, animados por algunos cipreses que recuerdan los fondos pictóricos florentinos y sieneses de Giovanni di Paolo y Sassetta. Estos árboles encuadran a santos y profetas que, arqueados o erguidos, se acomodan al ojo interno de la letra o se distribuyen a ambos lados en las $I$ y $M$. En el primer plano pueden encontrarse losetas ajedrezadas que quedan cortadas por el césped del fondo. Los ropajes son lisos y siempre plegados con grandiosidad, como en los frescos de San Isidoro del Campo, pero su tratamiento, incluso en los árboles, indica diversas manos o diversos talleres y épocas, tal y como aparece en la documentación.

De todas ellas, la única que $D$.Angulo considera verdaderamente obra de Pedro de Toledo es la capital historiada de la misa de la Asunción de la Virgen (L. 4, f.26v), donde observó gran simetría y tensión rítmica ascendente propia de un artista que conoce la pintura italiana contemporáneos. La escena está tratada con monumentalidad y señala los espacios divino y humano: en el cielo la Virgen, coronada, es abrazada por su Hijo, mientras en la parte baja los apóstoles, en la tierra, se disponen rodeando el sepulcro ${ }^{56}$. La composición de la letra y el marco del folio evidencian, aún más, los conocimientos pictóricos e iluminísticos de Pedro de Toledo. El cuerpo de la capital está centrado por motivos granados semejantes a los sieneses y florentinos contemporáneos. La orla, en la justificación izquierda, superior e inferior, presenta ritmo circular con follajes formando roleos en cuyo interior aparecen, jugando con la decoración, animales, seres míticos e híbridos, dragones, personajes desnudos, rosáceas....; la composición, de gran simetría, se rellena con tallos de intenso color verde terminados en flores y zarcillos rematados en florecillas trilobuladas de botón dorado. La aparición de estos elementos animados en la orla, que aluden al triunfo de Cristo y María sobre el mal, carece de antecedentes dentro de la miniatura sevillana, pero puede rastrearse en un Misal Romano de 1428, atribuido a Nicola di Ulisse da Siena ${ }^{57}$, y el desarrollo de los elementos fitomorfos no es lejano a Lorenzo de

56. ANGULO,D. (1928); ANGULO,D. (1984) pp.513-523 .

Esta capital historiada es la de mayor tamaño ( $320 \times 340 \mathrm{~mm}$.) si la comparamos con las demás ( $210 \times 190 \mathrm{~mm}$. y $100 \times 90 \mathrm{~mm}$.) y quizá se deba no sólo a su importancia dentro de la Iglesia Universal sino también de Sevilla, en particular, donde es titular de su catedral.

57. Siena Bibl. Comunale cod. X.II.2 f.7r. Sobre éste Vid.: CHELAZZI, G. Fienze 1982, Il gotico in Siena pp.371-376. 
Mónaco, lo cual demuestra la sintonía temporal de Pedro de Toledo respecto a los modelos toscanos pero que él interpreta de forma personal.

Los inicios de los Gloria, Patri, Kirie y Aleluyas de los libros de coro tienen un empleo constante de composiciones simétricas en los elementos filomorfos que ocupan totalmente los espacios dejados vacíos por la inicial, formando una fantasía inagotable de modelos ya en solitario, ya asistidos por cuadrifolias, racimos, sarmientos, flores abiertas en abanico y caprichosas flores compuestas. Éstos se encuentran también en los misales conservados en la Biblioteca Capitular, a través de los cuales disponemos de una cronología datada para la decoración de las letras y marginalia miniados. En ellos se observa una continuidad y evolución de los modelos fijados en la década de los treinta que perdurará, en algunos casos, hasta el tercer cuarto del siglo XV aunque tienden a dejar más limpio el fondo del pergamino. Estos modelos debieron circular por los distintos talleres de iluminación sevillanos. Fueron empleados más tarde en los marginalia del Evangeliario firmado por Pedro Guillen de Urrea en 1474, que están directamente inspirados en los prefacios musicales ${ }^{58}$. A su vez, quizá, sirvieran como motivo inspirador para la pintura mural si comparamos algunos con los paneles decorativos de San Isidoro del Campo.

Por todo el ello la decoración de este misal mixto realizado por el copistailuminador Pedro de Toledo es de gran importancia para el conocimiento de la introduccion de las corrientes internacionales en Sevilla y Andalucía occidental. Este iluminador, cuyo origen no conocemos, desarrollaba ya unos caracteres propios del pleno internacional meridional antes de lo que se suponía y debía mantener relaciones con Italia, que a lo mejor fueron el motivo de su viaje. Posiblemente otros pintores tendrían también esta tendencia, si tenemos en cuenta algunos rasgos que se aprecian en la Virgen de los Remedios de la catedral de Sevilla (h. 1400) y los rasgos de la tabla de García Fernández, documentado 1402 y 1420 , conservada en el convento de las Úrsulas de Salamanca.

En la década de los cincuenta se detecta pictóricamente una convivencia de estos modelos junto a otros de carácter nórdico que conformarán tempranamente la miniatura hispanoflamenca en Sevilla. Es, por tanto, un momento semejante, de cambio, al del primer tercio del siglo cuando se llevo a cabo, en fechas aún no, excesivamente, precisas la entrada del gótico internacional. Los códices conservados de la segunda mitad del siglo XV presentan una decoración enraizada en los modelos de ascendencia italiana de la década de los treinta y hasta fines de siglo no se perciben nítidamente las formas pictóricas flamencas y eckyanas. No

La pérdida de la misa de Pascua impide saber si originariamente pudo tener relaciones con la composición de la orla en este cantoral pues es la única, de todo el misal de Pedro de Toledo que, sabemos, tenía roleos en su composición.

58. LAGUNA, T. (1993) en prensa. 
obstante de época del arzobispo D. Juan de Cervantes (1448-1453) se ha conservado un códice de su biblioteca ${ }^{59}$ cuyo frontispicio muestra una vegetación más realista y un estilo internacional vinculable a las corrientes franco-flamencas contemporáneas, que debe obedecer a los gustos artísticos del prelado. No sabemos, con seguridad, si es obra sevillana pero interesa destacar la sintonía cronológica entre el códice y el sepulcro del prelado, encargado a Lorenzo Mercadante de Bretaña en 1454, así como la asimilación de formas hispano-flamencas en la pintura del sevillano Juan Sánchez de Castro (1454-1484) quien, sabemos, también realizo iluminaciones para la catedral no localizadas ${ }^{60}$.

Los libros corales de mediados del siglo XV continuan empleando orlas con elementos filomorfos dispuestos geométrica y simétricamente, pero han variado estilísticamente. D. Diego Angulo, que conocía unos pagos efectuados a Nicolás Gómez en 1454, indicó en una escena del L. 60 f. 21v un carácter diferente, pero también se la atribuyó al Maestro de los Cipreses y a Pedro de Toledo en quien vió una evolución estilística ${ }^{61}$. Además hoy en día se conoce que en el mismo año otro iluminador, Francisco Sánchez, percibe pagos por responsos de puntos grueso para la noche de Navidad ${ }^{62}$. Actualmente en un mismo libro coral (L. 60) hay dos folios que pudieran corresponder a éstos pagos, pero cuya autoría precisa no puede establecerse, de momento, al carecer de una miniatura localizada y datada de alguno de los dos que permitiría confrontar sus caracteres y estilos.

La escena del actual f.21v "Puer natus est nobis...." podría corresponder tanto a la misa de Navidad como al domingo de la octava de Navidad cuyo contenido vincularía a ambos miniaturistas por el libro en el cual pudieron encontrarse originariamente. Esta capital historiada está tratada como la miniatura flamenca del siglo XV y se desarrolla bajo un cobertizo de paja donde los animales están separados de la Familia por una valla trenzada. Sus antecedentes están claros en la miniatura del 1400: es propia de la iluminación flamenca, fue adoptada como elemento compositivo del paisaje en códices desde fines del siğlo XIV, incluso tablas como la Natividad de Giusto de'Menabuoi (1367) de la National G. de Londres, y a comienzos del siglo XV lo emplean Paul de Limbourg o el maestro de Boucicaut entre otros. Quedó como un motivo recurrente en los paisajes de artistas del norte e incluso aparece también en escultura como

59. B.C.C. $81-6-15$ f.1r. Las joyas.... N. .67.

60. GESTOSO, J.: Diccionario T. I p. 317. MURO OREJÓN, A.: "Pintores y doradores", Documentos para la Historia del Arte en Andalucía, Sevilla 1954, T. VIII, pp. 11-12. ÁLVAREZ, C. (1987)17-18.

61. GESTOSO, J.: Diccionario... T. I p.318-319. ANGULO, D. (1928) pp. 78 y 96. ANGULO, D. (1984) p. 515. El pago también está recogido junto con otros por ÁlVAREZ, C. (1987) p. 15 donde todos indican el pago de seis letras y orlas para el libro que comienza "In excelso trono", que corresponde al introito de la octava de la Epifanía.

62. ÁlVAREZ, C. (1987) p.5 
puede apreciarse en el tímpano de la portada del naciniento de la catedral de Sevilla encargado a Mercadante de Bretaña en 1454. En el mismo coral, en otra capital historiada, hay una escena de la Epifanía (f. 37r "Ecce ad ve...") donde podemos observar la misma arquitectura y el tratamiento de los Reyes Magos y corresponde indudablemente a las modas que llegaron del norte. Si se analizan las orlas de ambos folios no cabe duda que los dos deben corresponder a alguno de éstos pagos de 1454: su tratamiento difiere de los iluminados por Pedro de Toledo. Indican una asimilación de la pintura y miniatura flamenca por parte de los iluminadores sevillanos, constatada en escenas y decoraciones de los misales sevillanos, datados y datables, realizados entre 1450 y $1464^{63}$, y sincrónica a la llegada a esta ciudad de Mercadante de Bretaña pero realizada bajo una nueva dirección estética: una voluntad artística nueva y diferente.

Estas dos letras historiadas hispanoflamencas de 1454 indican no sólo un cambio estético, sino que son diferentes a las de la primera mitad del 1400 y a los caracteres analizados en Pedro de Toledo. Este artista junto a otros, que aún no son bien conocidos, realizan iluminaciones enraizadas en la tradición del siglo XIV junto a otras influencias propias del gótico internacional italiano durante el primer tercio del siglo XV. A partir de estas fechas puede considerarse que existe, ya, una auténtica escuela de iluminación sevillana, con rasgos y evolución propia, realizadas por los distintos artistas y talleres de la ciudad. 


\section{APÉNDICE DOCUMENTAL}

Liquidación que el mayordomo de la Fábrica de la Iglesia catedral de Sevilla, Juan Martínez de Vitoria, hace a Pedro de Toledo por la escritura y la iluminación de un Misal Mixto en cuatro tomos correspondiente a los años $1430-1433$.

A.- A.C.S., Sec. Fondo Histórico General, Caja 156, doc.núm. 17/1 fols. 11v$13 r$.

CIT. Carmen ÁLVAREZ MÁRQUEZ: "Notas para la historia de la Catedral de Sevilla en el primer tercio del siglo XV" Laboratorio de Arte 3 (1990) pp. 15-17. Elena RODRÍGUEZ DÍAZ: "Un misal hispalense del siglo XV. Estudio paleográfico y codicológico", Historia, Instituciones, Documentos 17 (1990) 195-229.

Fol. 11v

El Libro misto que fizo Pedro de Toledo

Pedro de Toledo escrivió un libro misto en quatro cuerpos e escrive todo sisterno por çiento mrs syn las letras cardinales.

- Iten las letras cabdinales fázelas todas de oro e azul e colores e pone el oro e colores, e yo el azul, e fázelas a este preçio.

- Faze las letras cabdinales todas commo la primera que está en comienço del primero cuerpo a LX mrs.

- Iten las letras de los ofiçios de las dominicas a XV maravedís.

- Iten las letras de los ofiçios de las ferias e de las fiestas a tres maravedís.

- Iten las letras de las oraçiones e evangelios e epístolas a maravedí

- Iten las letras de los responsos e aleluyas a XV dineros.

- En esto (sic) primero cuerpo asy en todo él escriptos XX çisterrnos e VII fojas con el calendario.

- Destas escrivio Juan García, sacristán, ocho çisternos a C maravedís que son $\mathrm{DCCC}^{\mathrm{a}}$ maravedís.

- Iten escriví Pedro de Toledo doze çisterrnos e siete fojas a este preçio que montaron M CC L VIII maravedís. 
Fol. $12 \mathrm{r}$

- Iten fizo Pedro de Toledo todas las letras cabdinales de dos (sic) estos XX çisterrnos e siete fojas que montaron con las estorias grandes que fizo en el " $\mathrm{Te}$ Igitur", por las quales se contaron CC L $\mathrm{L}^{\mathrm{a}}$, que montaron todas MM XL III maravedís.

- Iten ovo en el segundo cuerpo veynte çisternos e tres fojas escriptas, destas escrivió Juan García, sacristán, un çisterno por $\mathbf{C}$ maravedís.

- Escrivió Pedro de Toledo XIX çisternos e tres fojas que montaron al preçio sobredicho M D CCC XXV maravedís.

- Iten montaron las letras que fizo en este cuerpo e con trezientos maravedís que se contaron por las estorias del "Te Igitur", montan M D CC XCV maravedís.

- Iten ovo de aver más Pedro de Toledo de escriptura e yluminadura dos sisterrnos que se perdieron por yerro que ovo en la ordenança de los cuerpos, $\mathrm{C}$ LXX VIII maravedís.

- Iten perdióse vn sisterno de vn quaderrno de Juan García, sacristán, por la dicha ordenança, que son $\mathrm{C}$ maravedís.

- Dí por corregir al maestro de la escuela estos dos quadernos, CCCC maravedís.

- Iten costaron los clavos dorados que se pusieron en estos dos cuerpos con la costa del oro e del asentar, CC LXXX IIII maravedís.

Para el terçero cuerpo que se esquente.

- Cuenta rematada entre mí e Pedro de Toledo de los dichos dos cuerpos, de todo lo que ovo de aver e de todo lo que reçibio, alcançele de cuenta que me deve quinientos e diez e siete maravedís e medio

- Iten dile en XXV de jullio çinquaenta maravedís.

- Iten en seys dias de agosto dile çiento maravedís.

- Iten en XII de agosto dile çinquaenta maravedís.

- Iten en primero día de setiembre dile çinquaenta maravedís.

- Iten dile en XV de setiembre L maravedís.

- Iten dile en XIX de deziembre çiento maravedís.

- Iten dile en IX de enero, anno de XXXI, çincuenta maravedís.

- Iten en XIII de enero dile çinquaenta maravedís.

- Iten en XIX de enero dile çinquaenta maravedís.

Fol. 12v

- Iten en XXX de enero dile çinquaenta maravedís. 
- Iten en VII de enero (sic) dile doszientos maravedís.

- Iten en XIX de febrero dile treszientos maravedís.

- Iten en XXVI de febrero dile çiento maravedís.

- Iten en XII de março dile çíento maravedís.

- Iten en XXIX de março dile çiento e çinquaenta maravedís.

- Iten dile en IX de abril trezientos maravedís.

- Iten dile en XXVI de abril trezientos maravedís.

- Iten dile en siete de mayo çiento maravedís.

- Iten dile en XVI de mayo dozientos maravedís.

- Iten ha de pagar del alquile de la cámara seysçientos maravedís de los annos XXX e XXXI.

- Montó la escriptura deste terçero cuerpo

- Montaron las letras todas de las estorias

- Suma de todo lo que ovo de aver

- Suma de lo que tiene

- Asy finca que ha de aver M CCC XXX VIª , dígelos que se yva a Roma.

- Costaron texillos para los çerraderos destos libros XL maravedís.

- Dí por lo corregir al maestro CC maravedís.

- Costaron tres registros para los tres cuerpos, C XL V maravedís., los quales pesaron dos honças e quarta a quarenta maravedís la onça de la seda, e por las manos LV maravedís.

Quarto cuerpo:

- En XXIX de otubre, anno de XXXI dí a Françisco Sánchez escrivano de letra formada, de la escriptura que faze del quarto cuerpo del misto para la Eglesia, quinientos maravedís.

- En XIII de noviembre dile dozientos maravedís.

- En primero de deziembre dile çiento maravedís.

- En XII de deziembre dile çiento maravedís.

- En XXIIII de deziembre dile dozientos maravedís.

- En XIIII de enero, anno de XXXII dile dozientos maravedís.

Fol. 13r

- En VIII de abril dile çiento mrs.

- En XVI de mayo dile dozientos mrs.

- Dile por escrivir dos fojas del comienço, que se mojaron, que estavan ya escriptas XVIII maravedís V dineros

- Costó escrivir el calendario, que lo escrivió Pedro de Toledo, L marave- 
dís.

- Ovo en este cuerpo diez e seys sisterrnos, syn el calendario a CCL maravedís cada sisterrno que son MDC maravedís. Tiene tomados todos los maravedís segund está arriba escripto.

- Di a Pedro de Toledo en $\mathrm{V}$ de deziembre trezientos maravedís para las letras de oro que faze.

- Dile más en XV de deziembre trezientos maravedís.

- Dile en XXI de enero quinientos maravedís.

- Dile en II de febrero çiento maravedís.

- Dile en XIIII de febrero, CC maravedís.

- Dile en VII de março çiento maravedís.

- Dile en XXVI de março çiento maravedís.

- Montaron las letras deste quarto cuerpo MM C XX VIII ${ }^{a}$ maravedís.

- Iten ha de aver de la escriptura del calendario L maravedís.

- Iten ha de aver de la carta del çirio deste anno de XXX III, C XXX maravedís.

- De lo que ha de aver MM D CCC VIII maravedís V dineros

- Tiene tomados M CCC maravedís.

- Tiene diez ducados que la dió Luys Sánchez que valen D CCC XXX maravedís, asy quedan que ha de aver que alcança por LXX VIII maravedís V dineros, digelos e asy es acabada esta cuenta.

Nota marginal:

- Costaron las tablas para este libro VII maravedís.

- Costó el quaderno L maravedís.

- Costó clavar los clavos

- Costó fazer el panno VII maravedís. 


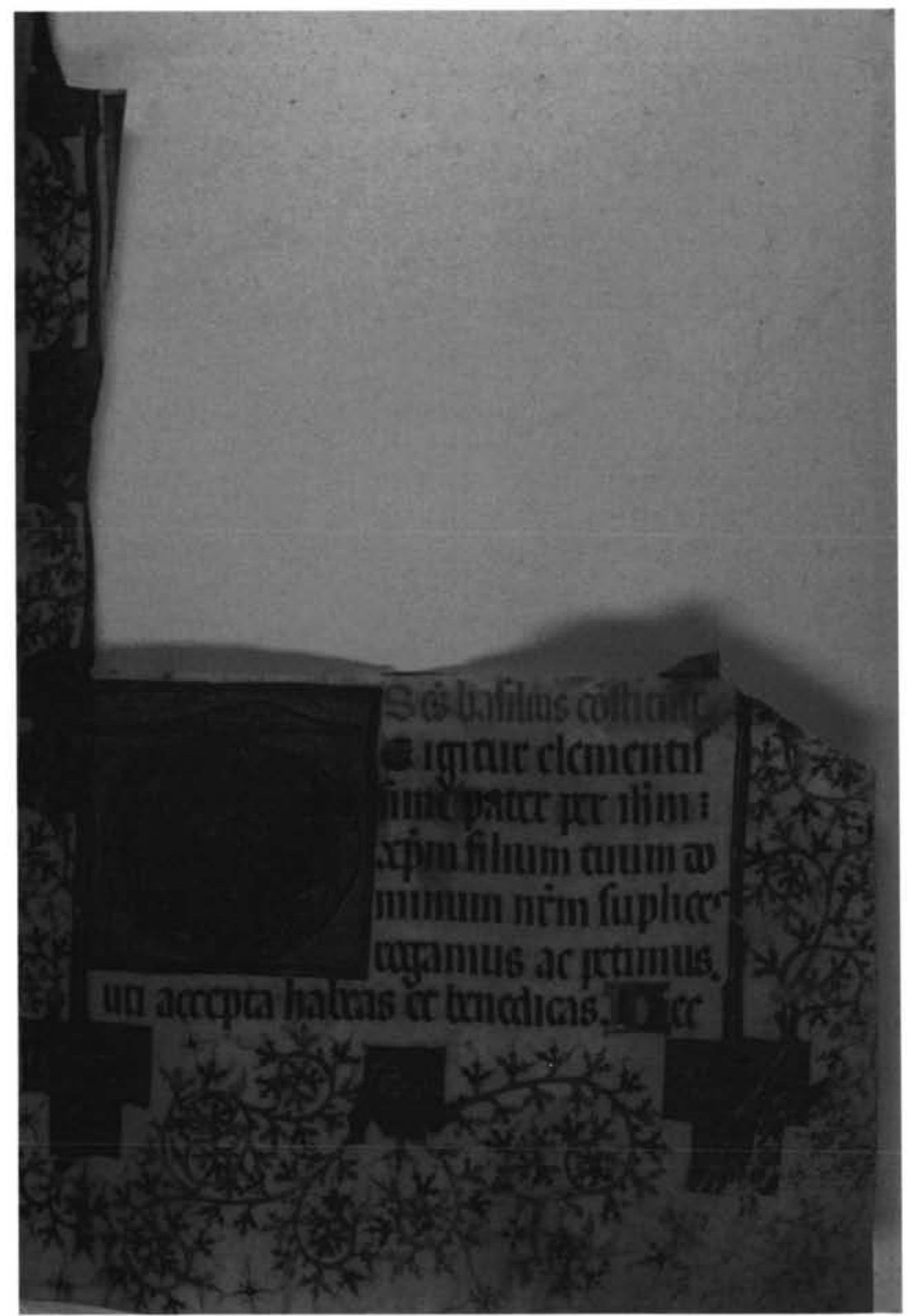

Lámina 1

Pedro de Toledo, Misal Mixto, vol. I Te Igitur

(Sevilla, Biblioteca Capitular y Colombina 85-8-7 c. 12 f. 1r) 


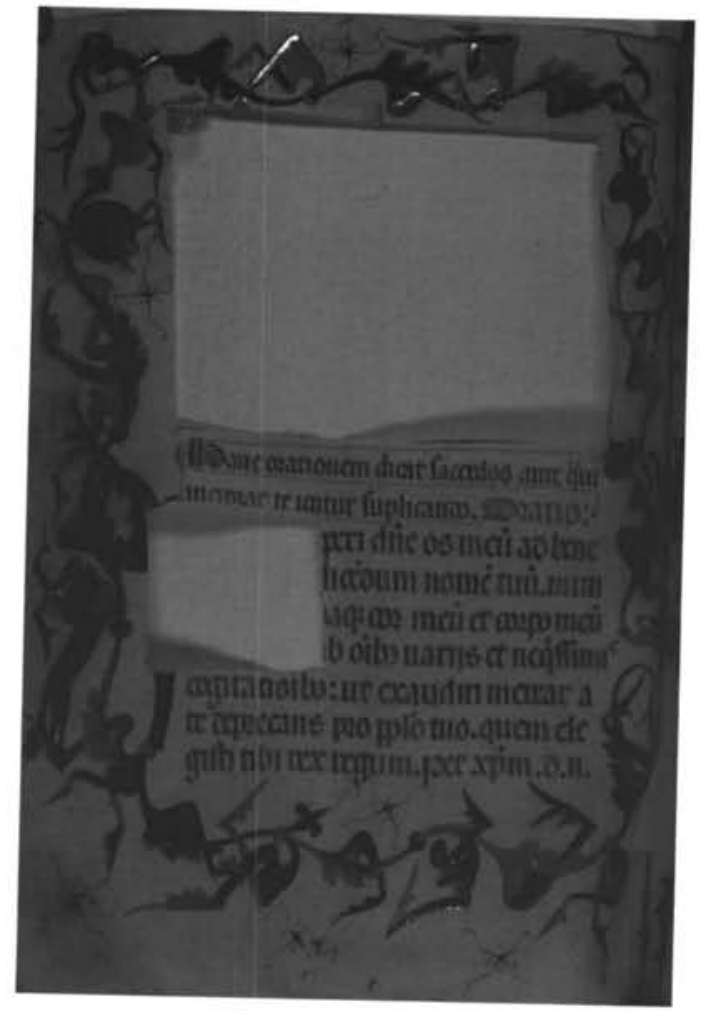

Lámina 2

Pedro de Toledo, Misal Mixto, vol. II Asperi te domine (Sevilla. Biblioteca Capitular y Colombina 85-8-6, c20 f. 4v)

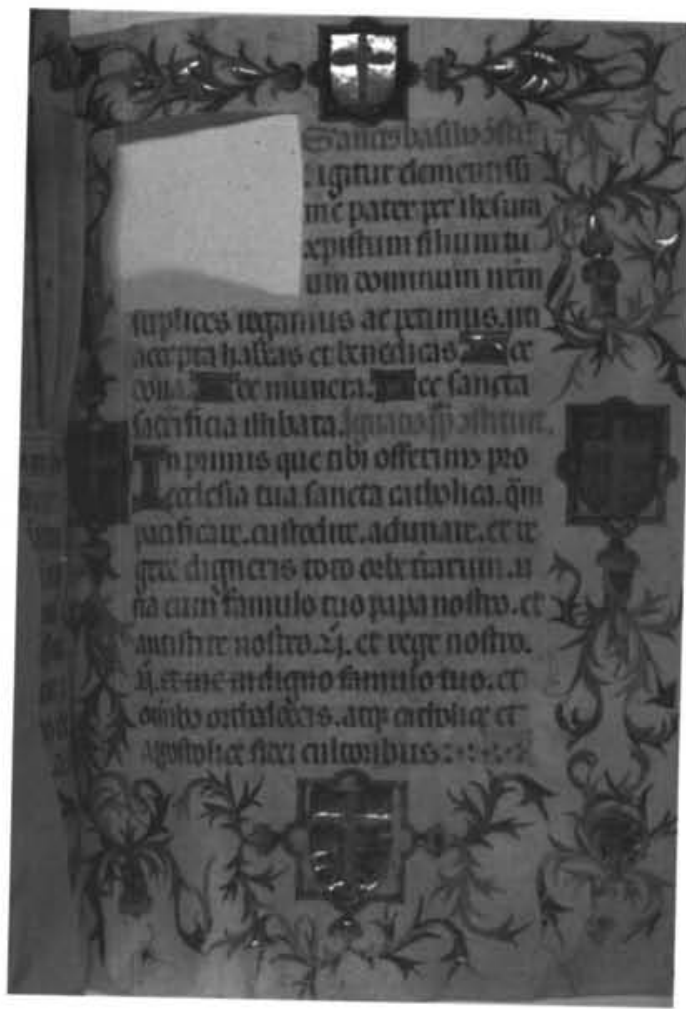

Lámina 3

Pedro de Toledo, Misal Mixto, vol. II Te Igitur (Sevilla. Biblioteca Capitular y Colombina $85-8-6$ c20 f. 5r) 


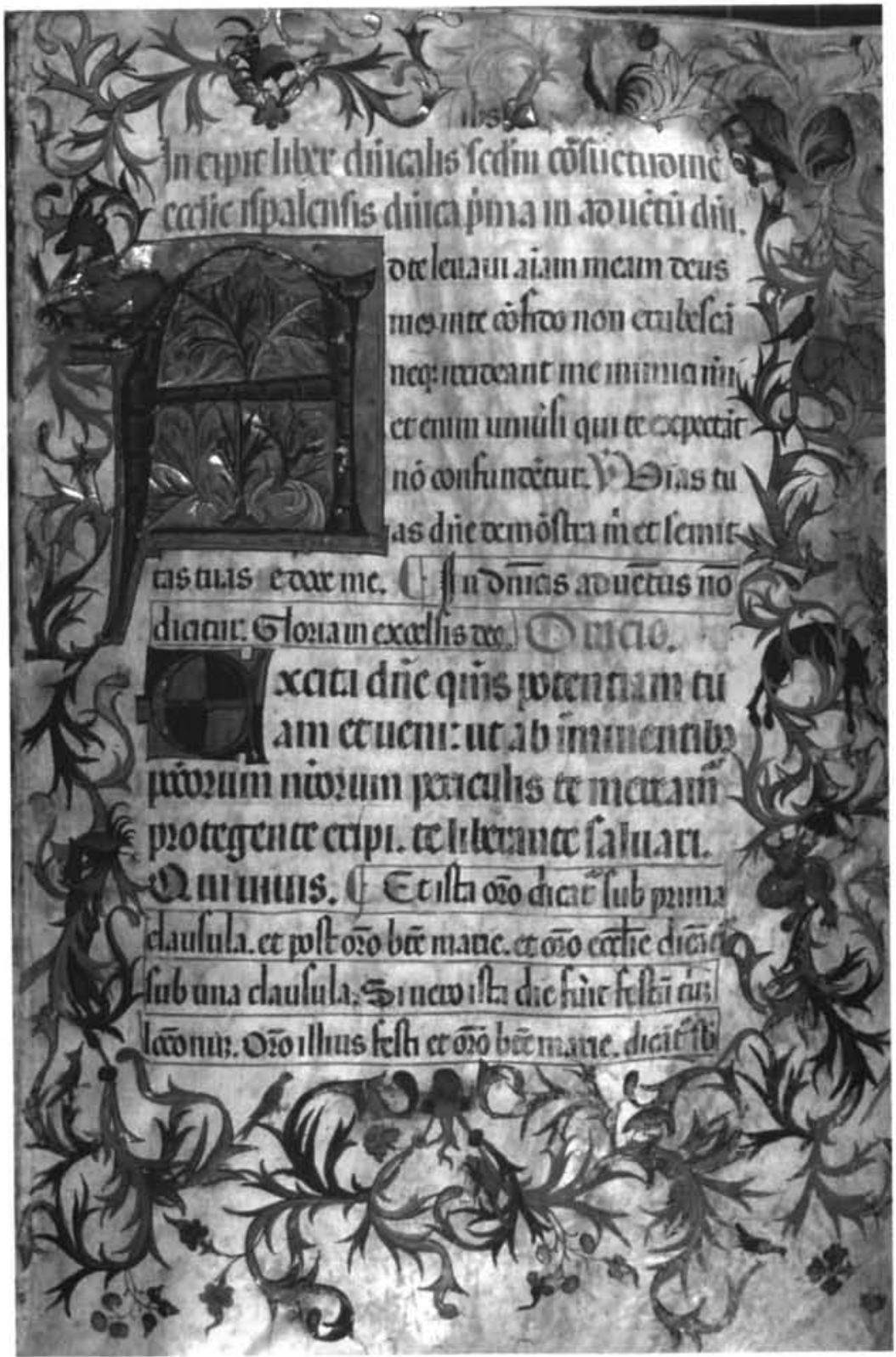

Lámina 4

Pedro de Toledo, Misal Mixto, vol. I Incipit del Temporal (Sevilla. Biblioteca Capitular y Colombina 85-8-7, cl f. 1r). 


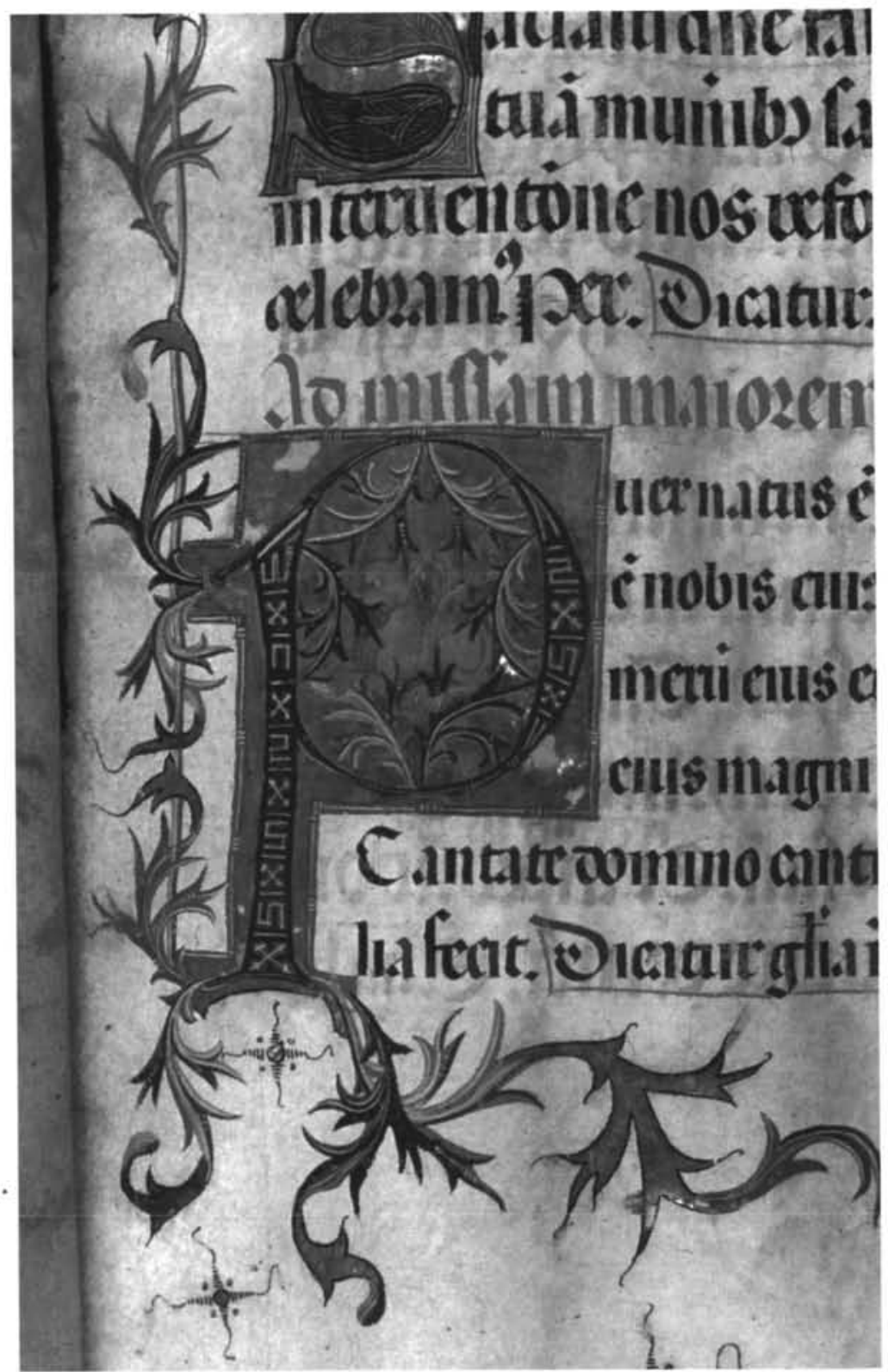

Lámina 5

Pedro de Toledo, Misal Mixto, vol. I Misa Mayor de Navidad (Sevilla. Biblioteca Capitular y Colombina 85-8-7 c3, f. 12r). 


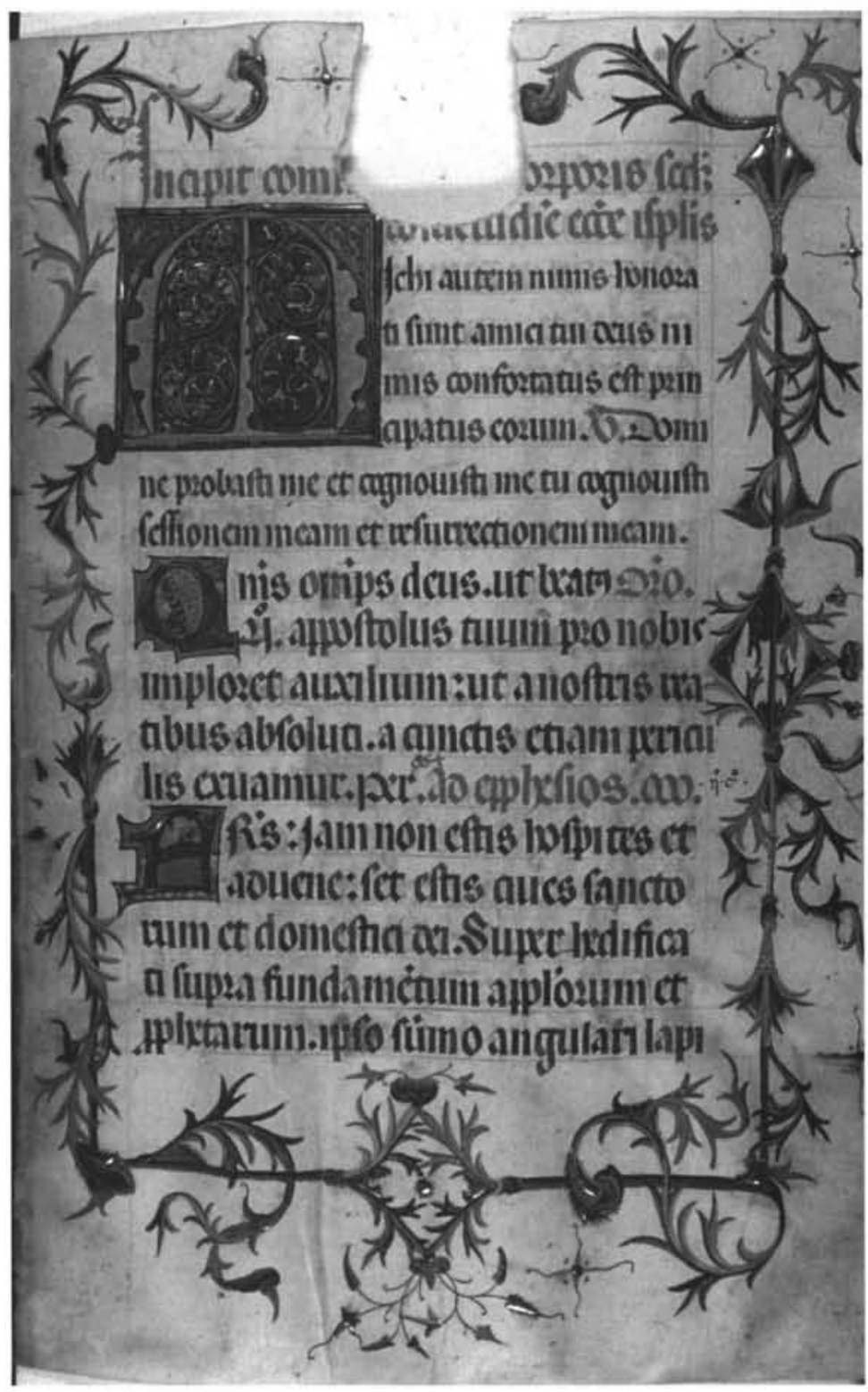

Lámina 6

Pedro de Toledo, Misal Mixto, vol. II Incipit del Común de los Santos (Sevilla. Biblioteca Capitular y Colombina 85-8-6 c23 f. 1r). 


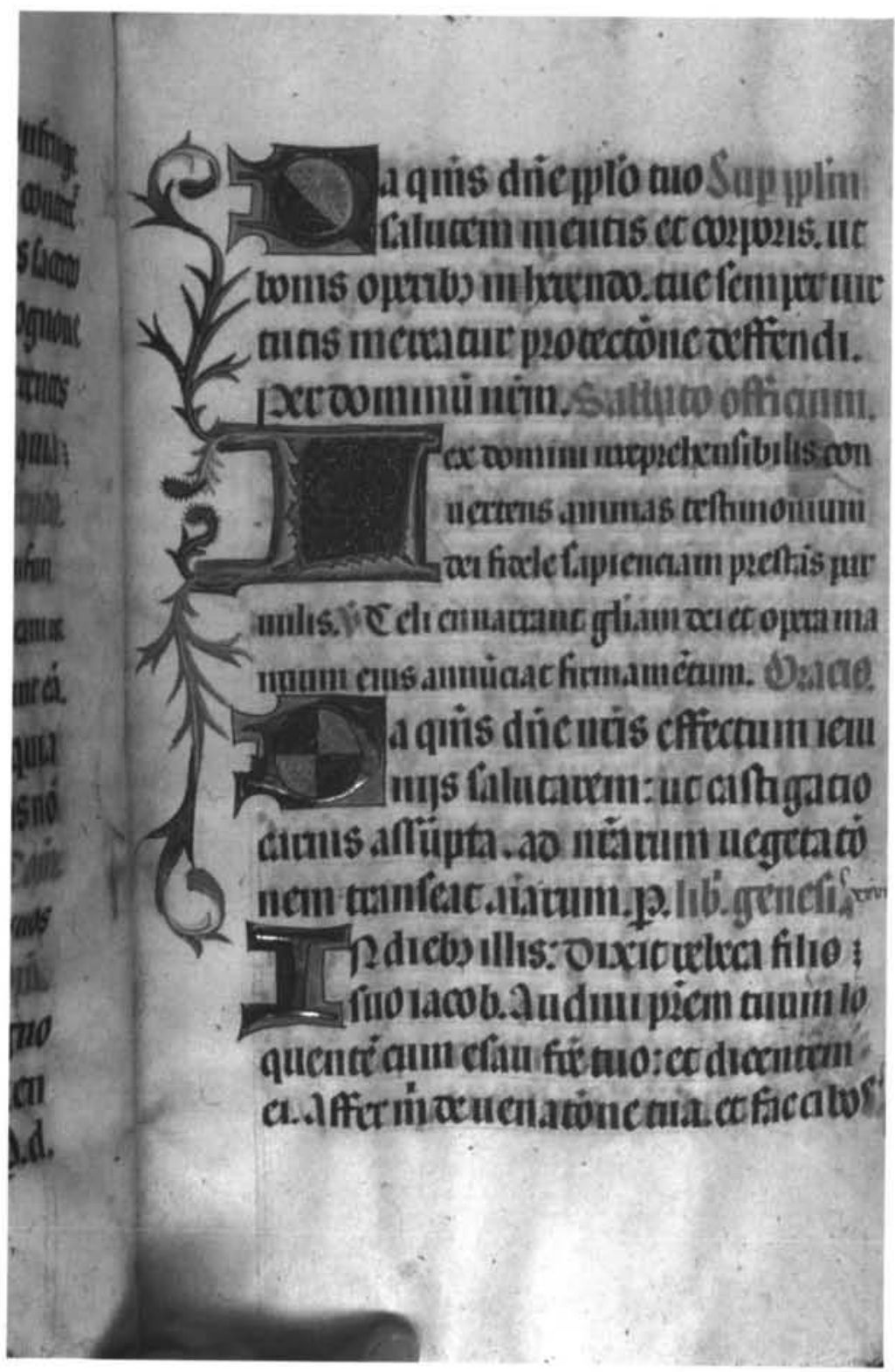

Lámina 7

Pedro de Toledo, Misal Mixto, vol. II Segundo Sábado de Cuaresma (Sevilla. Biblioteca Capitular y Colombina 85-8-6 c2, f. 10r). 


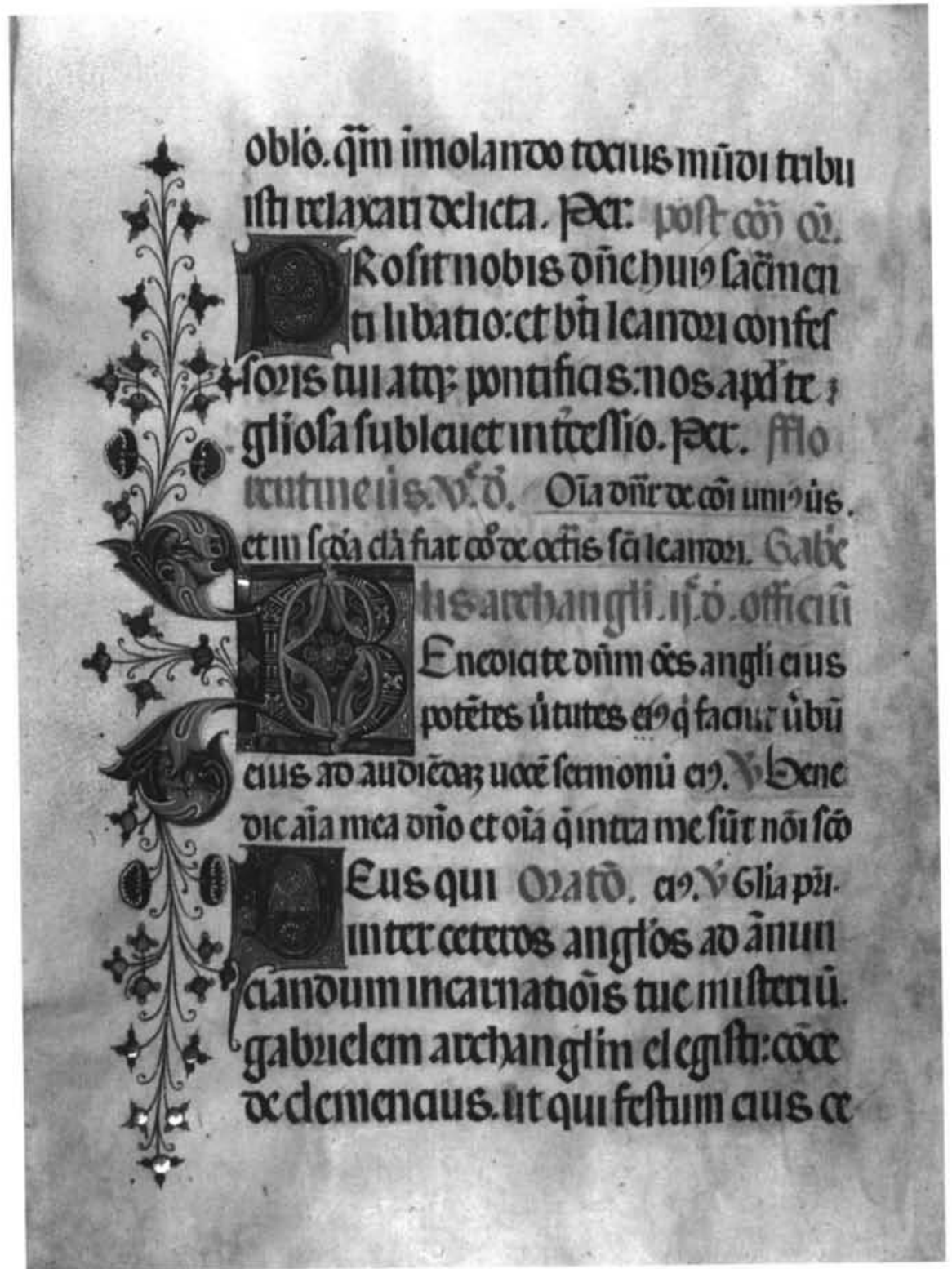

Lámina 8

Pedro de Toledo, Misal Mixto, vol. II Fiesta de San Gabriel añadida al Santoral Hispalense (Sevilla. Biblioteca Capitular y Colombina 85-8-6, c. 22, f. 4v). 


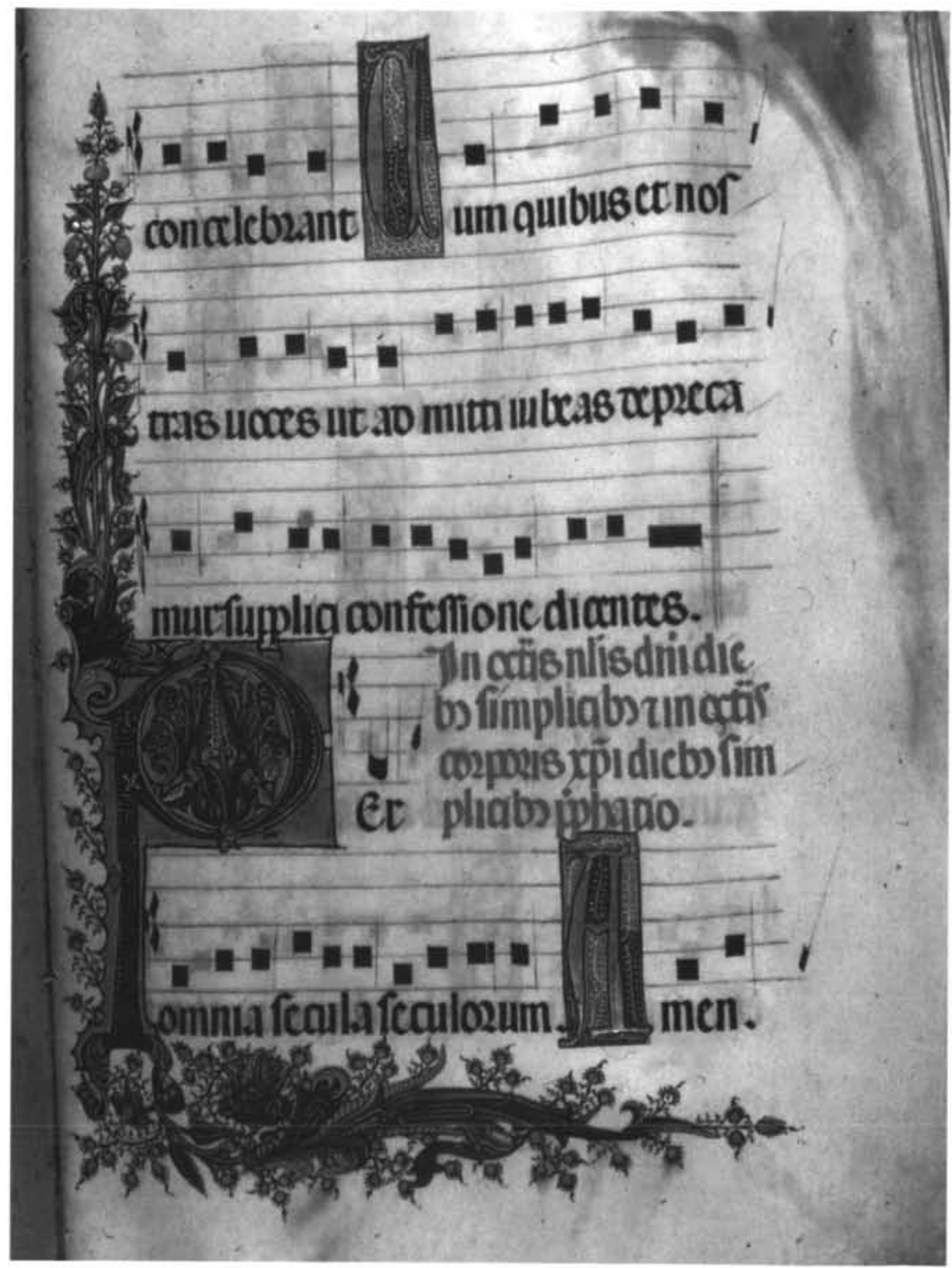

Lámina 9

Pedro de Toledo, Misal Mixto, vol. Prefacio musical (Sevilla. Biblioteca Capitular y Colombina 85-8-6 c. 17, f. 6v.). 


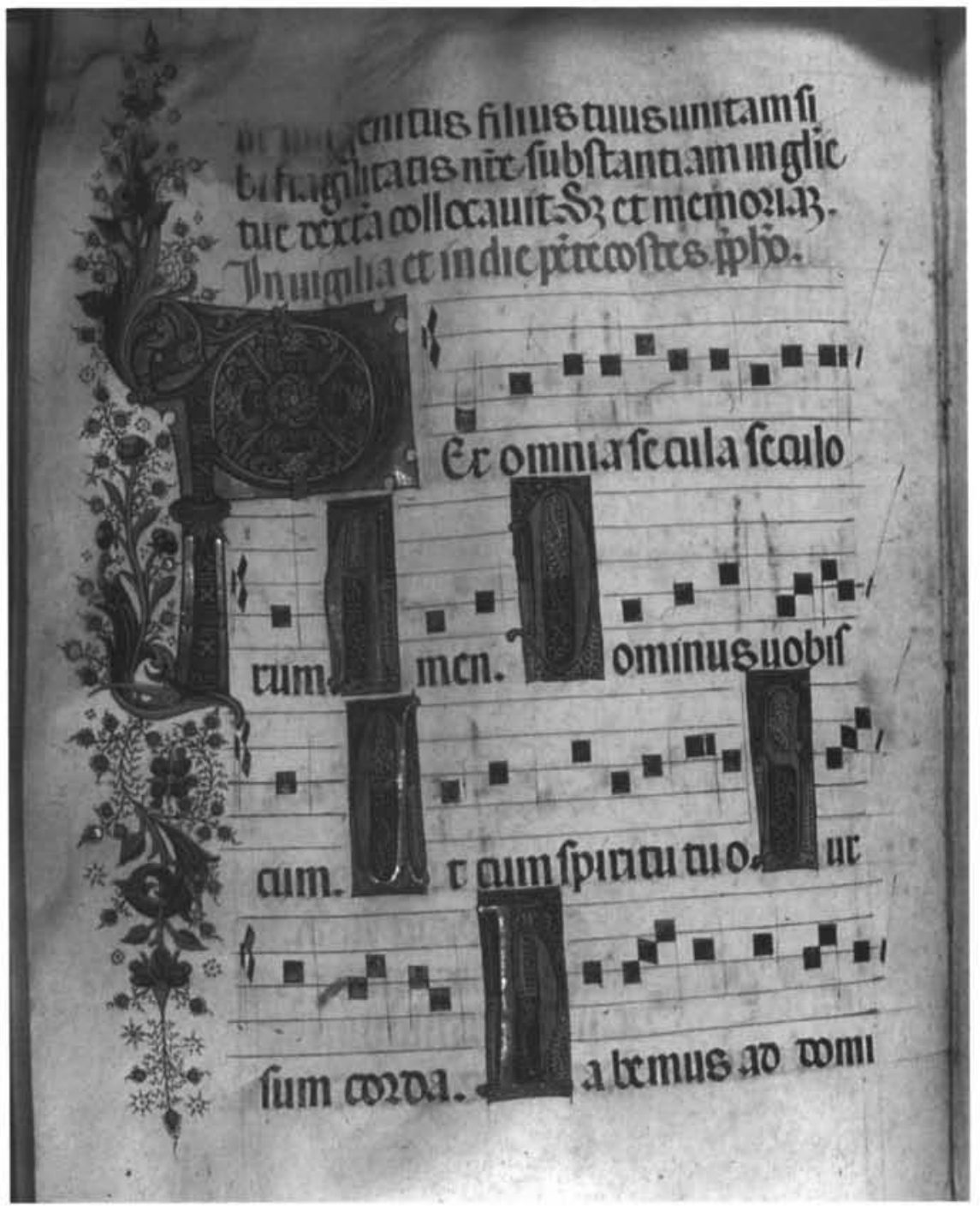

Lámina 10

Pedro de Toledo, Misal Mixto, vol. I Prefacio musical (Sevilla. Biblioteca Capitular y Colombina85-8-7 c13, f. 6v). 


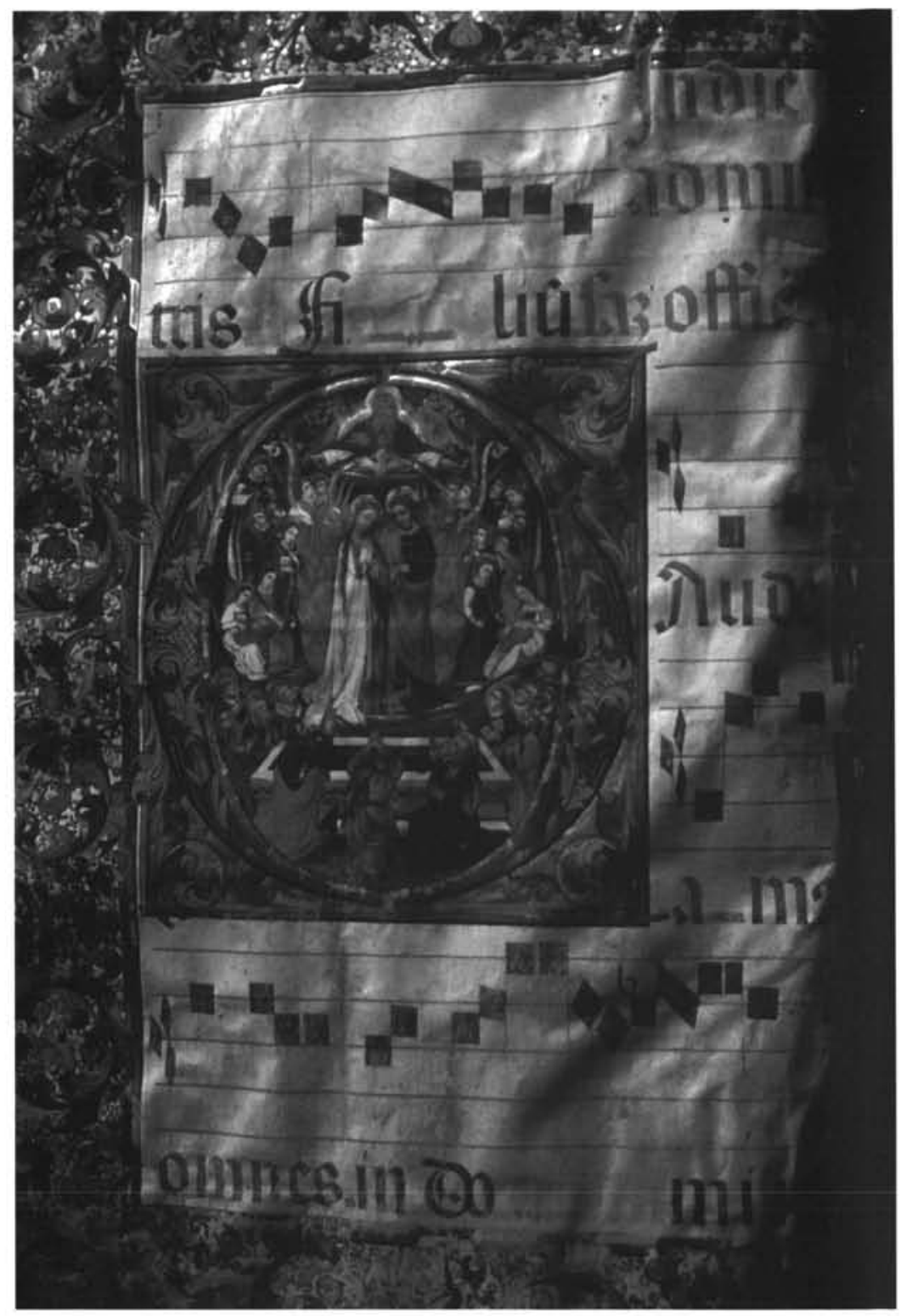

Lámina 11

Pedro de Toledo, Oficio del día de la Asunción (1434), Libro Coral (Sevilla, Catedral, librería coral L. 4, f. 26v). 


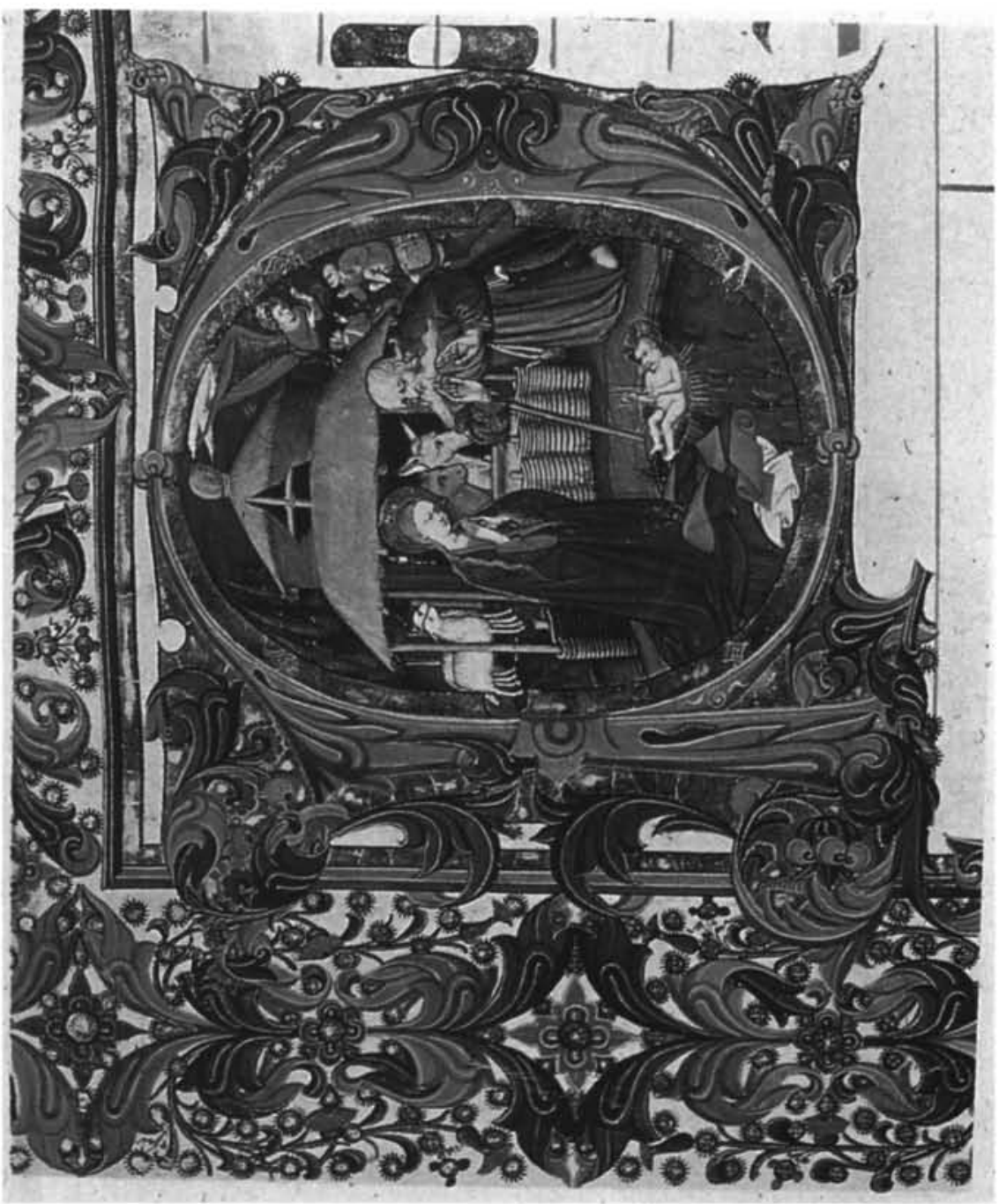

Lámina 12

Nicolás Gómez o Francisco Sánchez, Oficio, actual del día de Navidad (1454), Libro coral (Sevilla, Catedral, librería coral L. 60, f. 21v). 